\title{
Synthetic lethal targeting of oncogenic transcription factors in acute leukemia by PARP inhibitors
}

\author{
Maria Teresa Esposito ${ }^{1}$, Lu Zhao ${ }^{1}$, Tsz Kan Fung ${ }^{1}$, Jayant K Rane ${ }^{1}$, Amanda Wilson ${ }^{1}$, Nadine Martin ${ }^{2,5}$, Jesus Gil ${ }^{2}$, \\ Anskar Y Leung ${ }^{3}$, Alan Ashworth ${ }^{4}$ \& Chi Wai Eric So ${ }^{1}$
}

\begin{abstract}
Acute myeloid leukemia (AML) is mostly driven by oncogenic transcription factors, which have been classically viewed as intractable targets using small-molecule inhibitor approaches. Here we demonstrate that AML driven by repressive transcription factors, including AML1-ETO (encoded by the fusion oncogene RUNX1-RUNX1T1) and PML-RAR $\alpha$ fusion oncoproteins (encoded by PML-RARA) are extremely sensitive to poly (ADP-ribose) polymerase (PARP) inhibition, in part owing to their suppressed expression of key homologous recombination (HR)-associated genes and their compromised DNA-damage response (DDR). In contrast, leukemia driven by mixed-lineage leukemia (MLL, encoded by KMT2A) fusions with dominant transactivation ability is proficient in DDR and insensitive to PARP inhibition. Intriguingly, genetic or pharmacological inhibition of an MLL downstream target, HOXA9, which activates expression of various HR-associated genes, impairs DDR and sensitizes MLL leukemia to PARP inhibitors (PARPis). Conversely, HOXA9 overexpression confers PARPi resistance to AML1-ETO and PML-RAR $\alpha$ transformed cells. Together, these studies describe a potential utility of PARPi-induced synthetic lethality for leukemia treatment and reveal a novel molecular mechanism governing PARPi sensitivity in AML.
\end{abstract}

Since its application in BRCA1/2-mutated cancer in a decade ago, synthetic lethality induced by PARPis has given renewed enthusiasm to developing anticancer treatments that can specifically target cancer cells but spare normal tissue $e^{1,2}$. Although different underlying mechanisms have been proposed ${ }^{3,4}$, they are mostly attributed to critical functions of PARP in a variety of DNA-repair processes, including as a critical sensor of single-strand breaks (SSBs) in baseexcision repair $(\mathrm{BER})^{5,6}$; as a mediator for restarting stalled replication forks of HR-mediated double-strand break (DSB) repair ${ }^{7-9}$; and as a means of preventing the binding of Ku proteins to DNA ends in non-homologous end-joining (NHEJ) pathways ${ }^{10}$. Specifically, inhibition of BER impairs SSB repair, which results in accumulation of DSBs at the replication forks during the $\mathrm{S}$ phase of the cell cycle. DNA repair and survival of PARP-inhibited cells seem to be heavily dependent on HR, which is compromised in cancer cells carrying BRCA-related mutations ${ }^{11-17}$, leading to their unique susceptibility to PARPi treatment. There are also alternative but not mutually exclusive models in which PARPis may suppress transcriptional activity of PARP ${ }^{1,18}$ and/or function as poisons that result in PARP-DNA complex trapping and selective killing 4 .

In spite of its promise in breast and ovarian cancer, the clinical application of PARPis has not widely been translated to different cancers as an effective treatment, partly because mutations affecting DDR-associated genes are not common in other malignancies, including $\mathrm{AML}^{19}$, which is mainly driven by mutated transcription factors such as AML1-ETO, PML-RAR $\alpha$ and MLL fusions ${ }^{20}$. The same chemotherapy that was developed more than half a century ago is still used for nearly all AML patients, with the only exception being acute promyelocytic leukemia (APL), which carries a PML-RAR $\alpha$ fusion ${ }^{21}$. Owing to its high general toxicity, chemotherapy can usually only be applied to patients under age 60, leaving few or no treatment options for the majority of AML cases ${ }^{21}$. In addition, standard chemotherapy only induces less than $40 \%$ long-term complete remission and is mostly ineffective in patients carrying mutations in the KMT2A gene, which can be found in both AML and acute lymphoblastic leukemia (ALL) 21,36 . Therefore there is an urgent need to develop better therapeutic strategies for AML. Because specific transcriptional programs, including those involved in DDR, are frequently deregulated by various oncogenic transcription factors, we reasoned that transcriptional deregulation might represent an alternative mechanism that would allow the use of synthetic lethality approaches for effective leukemia treatments ${ }^{19}$.

\section{RESULTS}

Inhibition of PARP suppresses leukemia driven by AML1-ETO and PML-RAR $\boldsymbol{\alpha}$

To explore the therapeutic potentials of targeting PARP in acute leukemia, we investigated the effect of olaparib, a PARPi, on primary mouse hematopoietic cells transformed by the most common leukemia-associated transcription factors (LATFs), including

${ }^{1}$ Leukemia and Stem Cell Biology Group, Department of Haematological Medicine, Division of Cancer Studies, King's College London, London, UK.

${ }^{2}$ Cell Proliferation Group, Medical Research Council Clinical Sciences Centre, Imperial College London, London, UK. ${ }^{3}$ Department of Medicine, The University of Hong Kong, Hong Kong, China. ${ }^{4}$ University of California, San Francisco (UCSF) Helen Diller Family Comprehensive Cancer Center, San Francisco, California, USA. ${ }^{5}$ Present address: Senescence Escape Mechanisms Lab, Centre de Recherche en Cancérologie de Lyon, Lyon, France. Correspondence should be addressed to C.W.E.S. (eric.so@kcl.ac.uk).

Received 30 January; accepted 14 October; published online 23 November 2015; doi:10.1038/nm.3993 

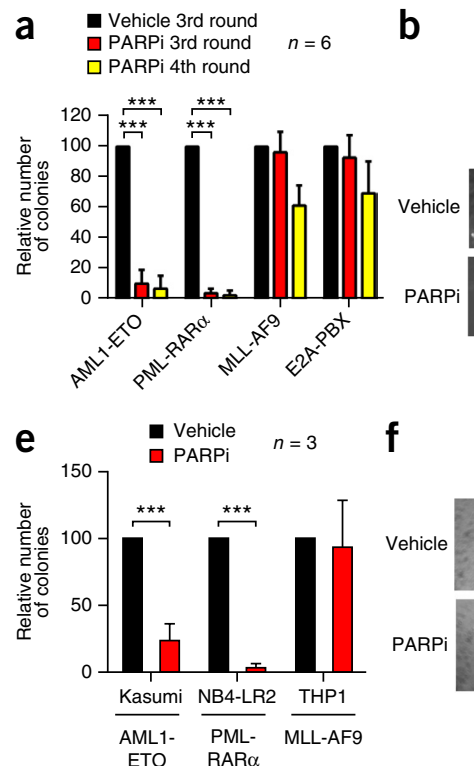

b

f

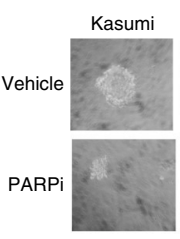

C

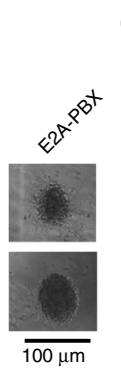

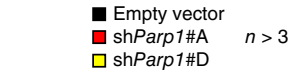

d

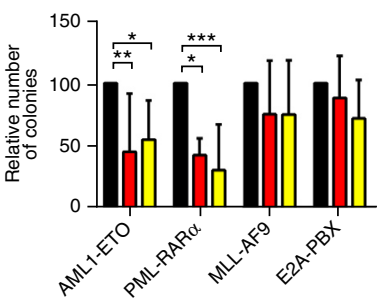

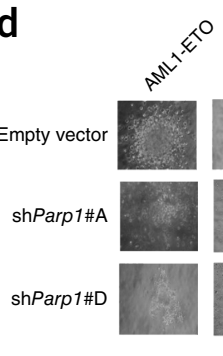

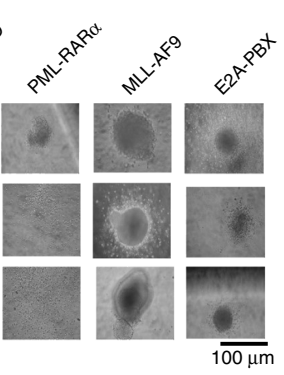

Figure 1 PARPi targets AML1-ETO- and PML-RAR $\alpha$-transformed leukemic cells in vitro and in vivo. (a) Relative number of colonies of leukemic cells surviving after treatment with olaparib, a PARPi. The number of colonies was acquired after $7 \mathrm{~d}$ of olaparib treatment in each round and data was normalized against the vehicle control. Data are mean \pm s.d. of six independent experiments. One-way analysis of variance (ANOVA) test was performed; $* * * P<0.001$. (b) Representative colony morphology with or without olaparib treatment. (c) Relative number of colonies of oncogene-induced leukemic cells transduced either with empty vector or shRNAs (shParp1\#A and shParp1\#D) targeting Parp1. The number of colonies was normalized against empty vector control. Data are mean \pm s.d. of three independent experiments. Two-way ANOVA test was performed; ${ }^{*} P<0.05,{ }^{* *} P<0.01,{ }^{* * *} P<0.001$. (d) Representative colony morphology of leukemic cells transformed by the indicated oncoproteins and transduced with empty vector or Parp1-targeting shRNAs (shParp1\#A and shParp1\#D). (e) Relative number of colonies of the human leukemic cell lines Kasumi (AML1-ETO), NB4-LR2 (PML-RAR $\alpha$ ) and THP1 (MLL-AF9), grown in methylcellulose for $7 \mathrm{~d}$. The number of colonies after PARPi treatment was normalized against the untreated control. Data are mean \pm s.d. of three independent experiments. One-way ANOVA test was performed; ${ }^{* *} P<0.001$. (f) Representative colony morphology of human leukemic cell lines treated with PARPi. (g) Kaplan-Meier survival curve of NSG mice transplanted with Kasumi cell lines treated with olaparib or vehicle (DMSO). (h) Kaplan-Meier survival curve of NSG mice transplanted with NB4-LR2 cells treated with olaparib or vehicle (DMSO). (i) Kaplan-Meier survival curve of NSG mice transplanted with THP1 cells treated with olaparib or vehicle (DMSO).

AML1-ETO, PML-RAR $\alpha$, MLL-AF9 and E2A-PBX, using the retroviral transduction/transformation assay (RTTA) ${ }^{22-25}$. Whereas a concentration of up to $1 \mu \mathrm{M}$ olaparib exhibited minimal effects on normal bone marrow, it had a notable effect on transformed primary cells. PARPi significantly suppressed the colony-forming ability of cells transformed by AML1-ETO or PML-RAR $\alpha$ by about $90 \%$, although it exhibited little impact on MLL-AF9- or E2A-PBX-transformed cells (Fig. 1a,b and Supplementary Fig. 1a-d). To confirm the specificity of the drug, we also reported very similar and selective leukemia-suppressive effects using a different PARPi, veliparib (Supplementary Fig. 1e,f). To show that PARP1 was the major molecular target for the observed phenotype upon PARPi treatment, two independent Parp1targeting shRNAs (Supplementary Fig. 1g,h) were used to deplete Parp1 in the RTTA. Consistently, both Parp1-targeting shRNAs significantly suppressed the colony-forming ability of cells transformed by AML1-ETO or PML-RAR $\alpha$, but not those transformed by E2APBX and MLL-AF9 (Fig. 1c,d and Supplementary Fig. 1i).

To investigate the effects of PARPi on the corresponding human leukemias, we used patient-derived leukemic cell lines carrying AML1-ETO (Kasumi), mutated PML-RAR $\alpha$ that is resistant to standard all-trans retinoic acid (ATRA) treatment (NB4-LR2) ${ }^{25}$, or MLL-AF9 (THP1) for the inhibitor studies. Analogously to the mouse models, PARPi reduced the colony-forming ability of Kasumi and NB4-LR2 cells, but not THP1 cells (Fig. 1e,f). To further demonstrate potential in vivo efficacy, these cells were xenotransplanted into immunocompromised mice and subjected to the PARPi treatment. Despite being used as a monotherapy, olaparib significantly delayed the disease onset driven by AML1-ETO from a median survival of 55 d to 102 d (Fig. 1g, Supplementary Fig. 1j,m, and Supplementary Table 1). Notably, olaparib as a single agent could also effectively suppress disease onset induced by ATRA-resistant APL cells (Fig. 1h, Supplementary Fig. 1k,n, and Supplementary Table 1). In contrast, PARPi had no effect on the survival of a xenograft mouse model transplanted with THP1 cells (Fig. 1i, Supplementary Fig. 11,o, and Supplementary Table 1). To further substantiate these findings, we also observed very similar differential in vitro PARPi responses from primary AML patient samples carrying the corresponding translocation fusions (Supplementary Fig. 1p,q). Together, these results reveal the potential therapeutic utility of PARPis in different subtypes of leukemia driven by specific LATFs, including AML1-ETO-driven leukemia and ATRA-resistant APL ${ }^{26}$.

\section{PARPi treatment induces differentiation and senescence}

Although PARPi can generally slow leukemic cell growth, PARPi treatment of AML1-ETO- and PML-RAR $\alpha$-transformed mouse cells resulted in their morphological differentiation into monocytic and granulocytic lineages (Fig. 2a,b and Supplementary Fig. 2a-d), which is consistent with recent observations of leukemic differentiation induced by excessive DNA damage ${ }^{27}$, suggesting that differential DDR may underlie the contrasting PARPi responses. PARPi treatment was also accompanied by cell cycle G1 arrest (Fig. 2c and Supplementary Fig. 2e), upregulation of Tp53 (also known as p53), Cdkn1a (also known as $p 21$ ) (Fig. 2d,e) and $C d k n 2 a$ (also known as p16) expression in AML1-ETO and PML-RAR $\alpha$-transformed cells (Fig. 2f), which 


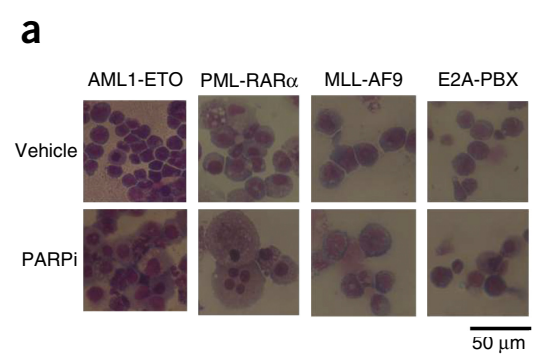

b $\quad$ Differentiated

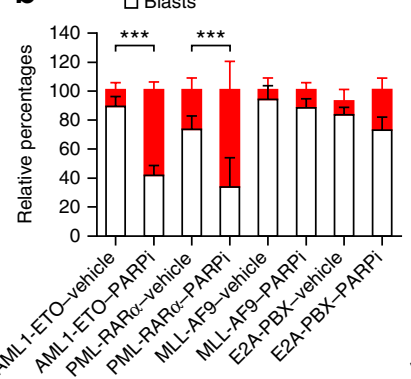

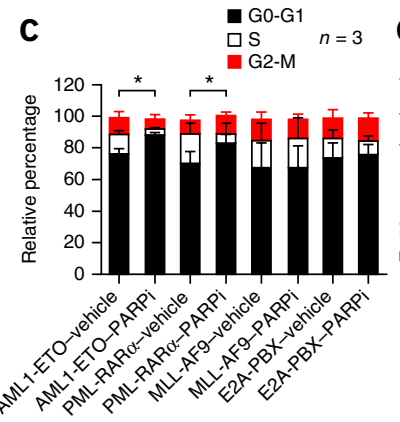
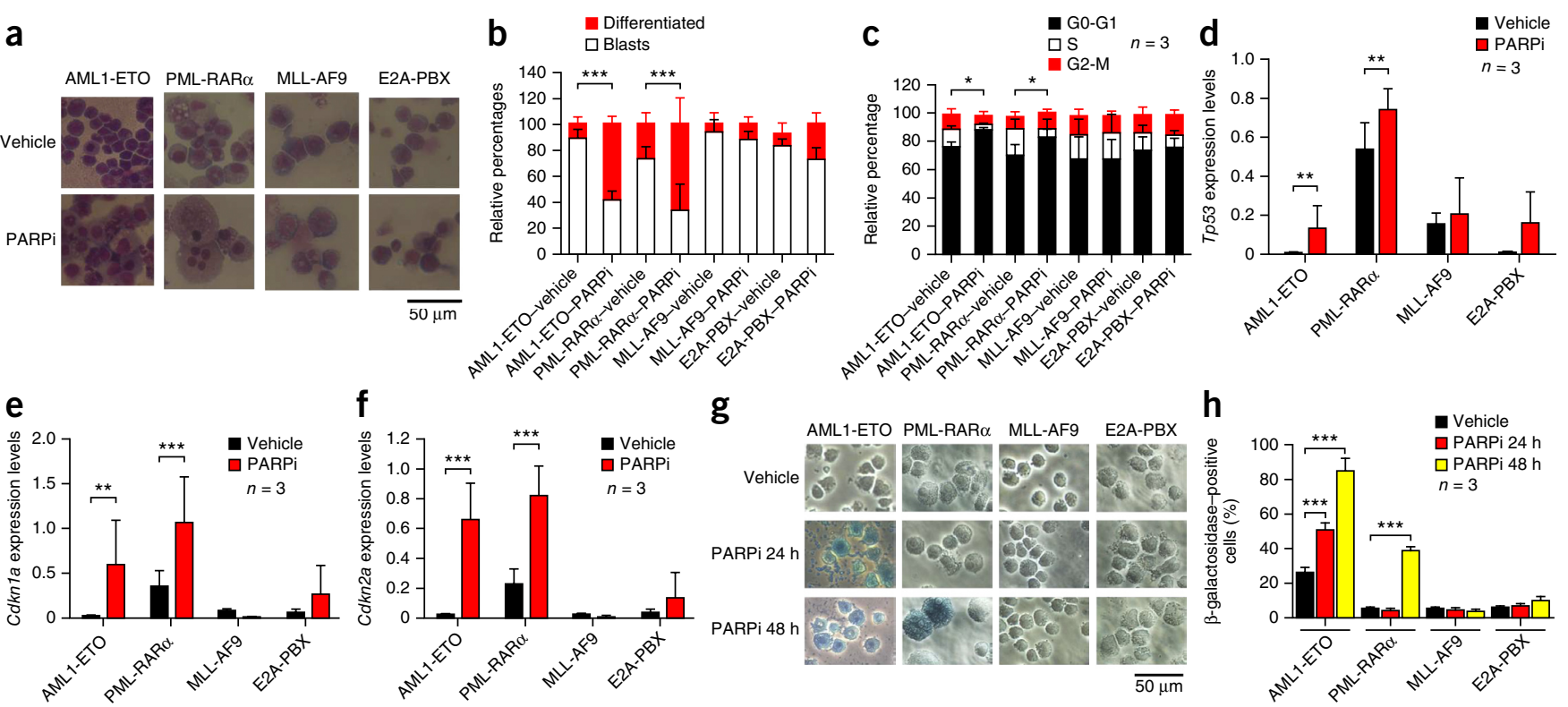

g

Figure 2 PARPis induce differentiation, senescence, and apoptosis of AML1-ETO- and PML-RAR $\alpha$-transformed leukemic cells. (a) May-Grunwald Giemsa staining of leukemic cells upon treatment with PARPi. (b) Quantification of morphologically differentiated cells in a. Data are mean \pm s.d. One-way ANOVA was performed; ${ }^{* *} P<0.001$. (c) Cell cycle analysis of leukemic cells after $48-72 \mathrm{~h}$ of continuous PARPi treatment. Data are mean \pm s.d. of three independent experiments. One-way ANOVA was performed; ${ }^{*} P<0.05$. (d-f) Expression of Tp53 (d), Cdknla (e) and Cdkn2a (f) in the indicated transformed cells after continuous PARPi treatment. Expression of the target genes was normalized against Gapdh $\left(2^{-\Delta C T}\right)$. Data are mean \pm s.d. of three independent experiments. Unpaired $t$-test was performed; ${ }^{*} P<0.05,{ }^{* *} P<0.01,{ }^{* * *} P<0.001$. (g) Representative image from three independent experiments showing $\beta$-galactosidase staining of primary transformed cells after $24 \mathrm{~h}$ and $48 \mathrm{~h}$ of PARPi treatment. (h) Quantification of percentage of $\beta$-galactosidase positive cells. Data are mean \pm s.d. of three independent experiments. One-way ANOVA test was

performed; ${ }^{* *} P<0.001$. (i) Quantification of percentage of annexin $\mathrm{V}^{+}$propidium iodide $(\mathrm{PI})^{+}$and annexin $\mathrm{V}^{+} \mathrm{PI}-$ cells upon PARPi treatment at $24 \mathrm{~h}$ and $48 \mathrm{~h}$. Data are mean \pm s.d. of six independent experiments. One-way ANOVA test was performed; $* * P 0.01$.

underwent significant senescence upon PARPi treatment (Fig. 2g,h). PARPi treatment also induced apoptosis of PML-RAR $\alpha$-transformed cells (Fig. 2i and Supplementary Fig. 2f). In contrast, none of these effects were observed in E2A-PBX- or MLL-AF9-transformed cells despite a small upward trend in differentiation and apoptosis (Fig. 2a-i). In accordance with the mouse data, PARPi could effectively induce senescence and apoptosis in Kasumi and NB4-LR2 cells but not THP1 cells (Supplementary Fig. 2g-i); and increased differentiation of primary AML cells carrying AML1-ETO and PML-RAR $\alpha$ fusions but not MLL fusions (Supplementary Fig. 2j-1). These results consistently suggest a specific requirement of PARP function in cells transformed by AML1-ETO and PML-RAR $\alpha$.

\section{AML1-ETO- and PML-RAR $\alpha$-transformed cells show inherent DDR defects}

Although the general rationale behind the PARPi sensitivity is a defect in $\mathrm{DDR}^{3,4,15,16,28}$, PARP also has transcriptional functions involved in gene regulation ${ }^{1,18}$. After failing to detect direct biochemical interaction (Supplementary Fig. 3a and M.T.E., T.K.F., N.M., J.G. and C.W.E.S., unpublished mass spectrometry data) and transcriptional regulation (Supplementary Fig. 3b-e) between PARP1 and any of the studied leukemia fusion proteins, we examined the kinetics of the DDR in primary transformed cells by analyzing Ser139-phosphorylated $\gamma \mathrm{H} 2 \mathrm{AX}$ foci, which are considered to be an early response to $\mathrm{DSBs}^{29}$. With the exception of E2A-PBX, untreated AML1-ETO-,
PML-RAR $\alpha$ - and MLL-AF9-transformed cells displayed significant levels of $\gamma \mathrm{H} 2 \mathrm{AX}$ DNA damage foci, indicative of ongoing DNA damage or replication stress (Fig. 3a,b and Supplementary Fig. 3f). Upon PARPi treatment, both PARPi-insensitive and PARPi-sensitive cells showed further induction of $\gamma \mathrm{H} 2 \mathrm{AX}$ foci (Fig. 3c and Supplementary Fig. 3g-k), suggesting that PARPi induced DNA damage regardless of the oncoprotein fusions. Then we investigated recruitment of the recombinase to DNA damage sites, as a readout of $\mathrm{HR}$ efficiency ${ }^{30,31}$. Upon PARPi treatment for $6 \mathrm{~h}$, E2A-PBX or MLL-AF9 cells were able to efficiently form RAD51 foci, which then returned to basal levels after the repair in $24 \mathrm{~h}$ (Fig. 3c,d and Supplementary Fig. 3g-j,1). In contrast, little RAD51 recruitment was observed in AML1-ETO or PML-RAR $\alpha$ cells, in which around $80 \%$ showed $\gamma \mathrm{H} 2 \mathrm{AX}$ and RAD51 foci ratio greater than 2 (Fig. 3e), indicating their HR-deficient nature. The observed differential HR deficiency associated with PARPi treatment is unlikely to be due to different cell cycle status of these cells, as PARPi exhibited no significant effect on cell cycle progression in the first $24 \mathrm{~h}$ (Supplementary Fig. 3m) when these assays were performed. To further extend our findings to human disease, we consistently observed higher levels of DNA damage in Kasumi and NB4-LR2 cells (Supplementary Fig. 3n,o), which also failed to effectively induce RAD51 foci upon PARPi treatment, as compared with THP1 cells (Supplementary Fig. 3p-r).

Next, we investigated and revealed a decreased expression of key HR genes including Rad51, Atm, Brca1 and Brca2 in both AML1-ETO 
a

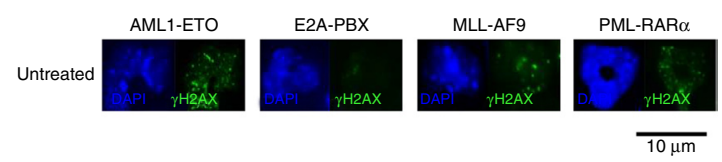

C
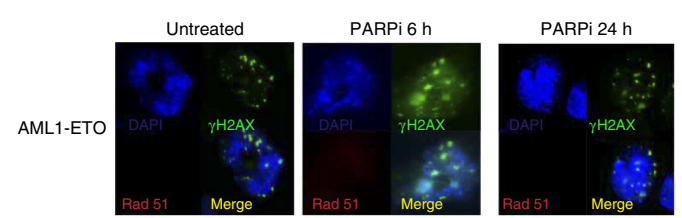

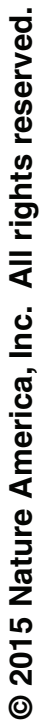
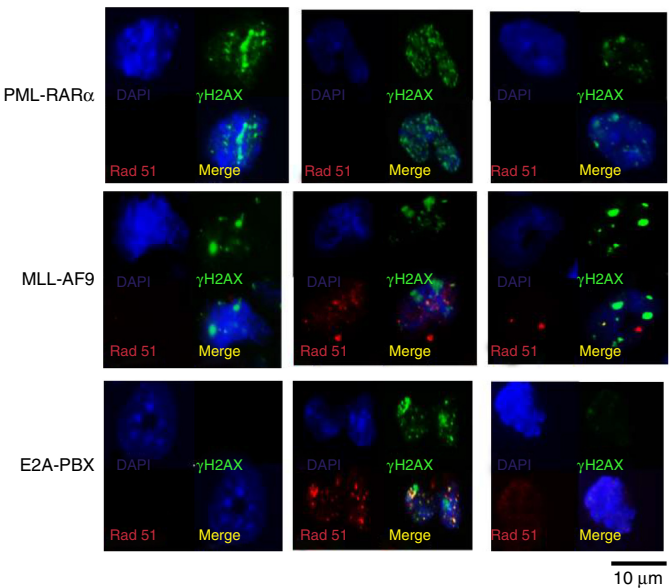

g b

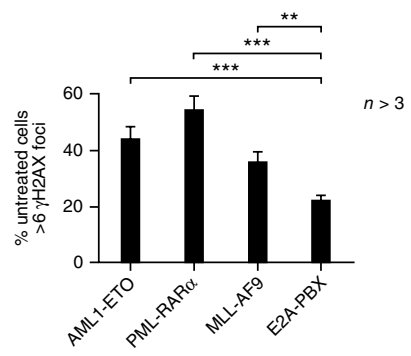

d

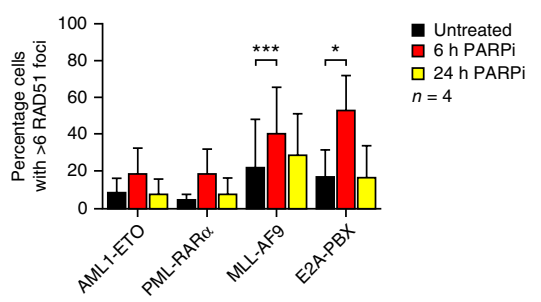

e

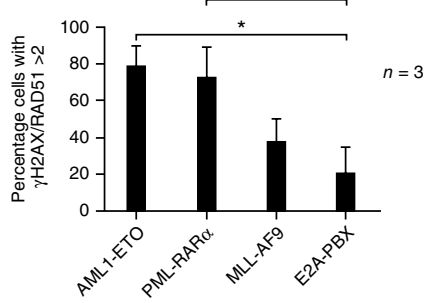

f
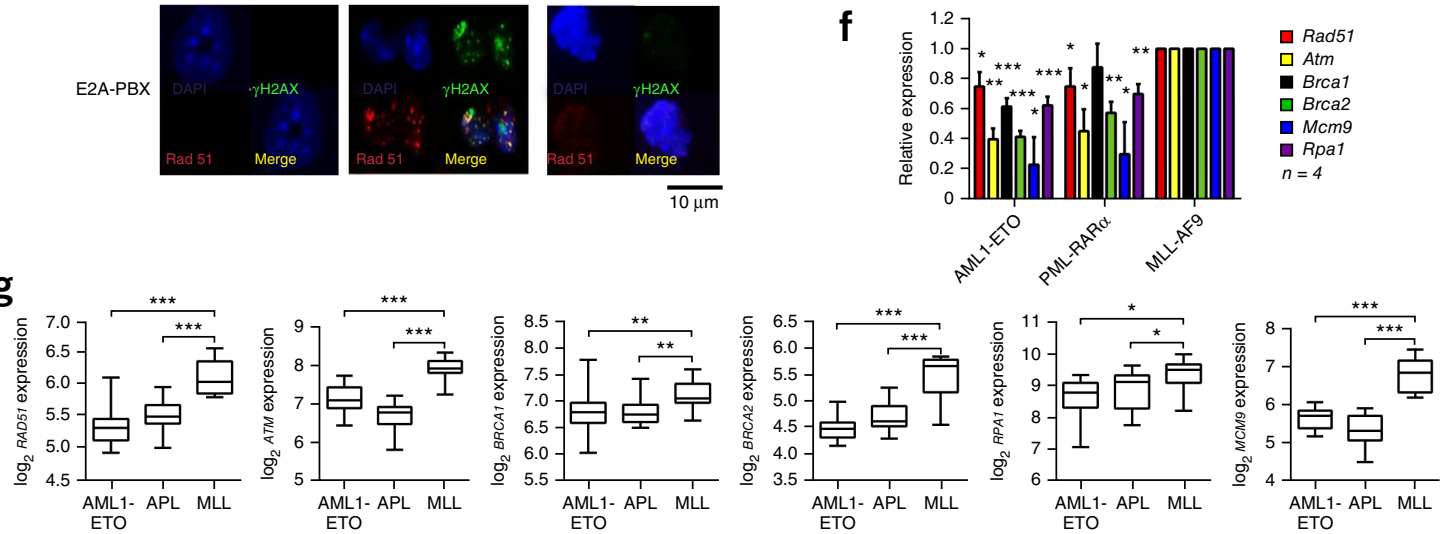

h
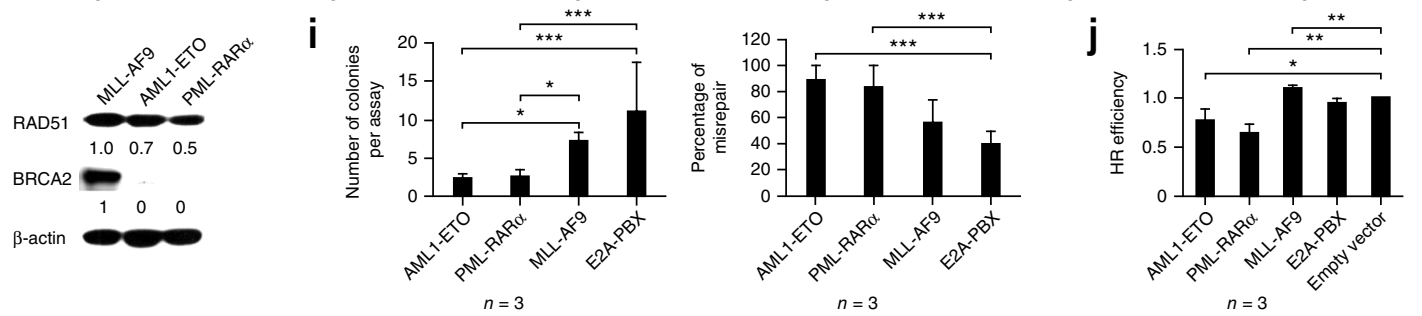

Figure 3 AML1-ETO- and PML-RAR $\alpha$-transformed cells show a defect in the HR pathway and accumulate DNA damage in response to PARPi treatment. (a) Immunofluorescence microscopy of $\gamma \mathrm{H} 2 \mathrm{AX}$ foci in untreated primary transformed mouse cells (representative cells). (b) Quantification of the percentage of cells with $>6 \gamma \mathrm{H} 2 \mathrm{AX}$ foci \pm s.d. One-way ANOVA test was performed; ${ }^{*} P<0.01,{ }^{* * *} P<0.001$. (c) Time-course analysis of PARPi induced $\gamma \mathrm{H} 2 \mathrm{AX}$ and RAD51 foci by immunofluorescence upon continuous PARPi treatment (representative cells). (d) Quantification of percentage of RAD51 positive cells upon PARPi treatment at the indicated time point. Data are mean \pm s.d. One-way ANOVA test was performed; $P<0.05 * * * P<0.001$.

(e) The percentage of cells with $\gamma \mathrm{H} 2 \mathrm{AX} / \mathrm{RAD} 51$ ratio $>2$ is shown, data are mean \pm s.d.; one-way ANOVA test was performed; ${ }^{*} P<0.05$. (f) $\mathrm{qPCR}$ showing relative expression of Rad51, Brca1, Brca2, Atm, Mcm9 and Rpal in primary mouse cells transformed by the indicated oncoproteins. Data are mean \pm s.d. One-way ANOVA was performed; ${ }^{*} P<0.05,{ }^{*} P<0.01,{ }^{*} * * P<0.001$. (g) Box plots showing the relative microarray expression of $R A D 51, A T M, B R C A 1$, $B R C A 2, M C M 9$ and RPA1 in AML patients carrying the AML1-ETO or PML-RAR $\alpha$ translocations (APL) or MLL fusions. Paired $t$-test was performed; ${ }^{*} P<0.05,{ }^{*} P<0.01,{ }^{* *} P<0.001$. (h) Western blot showing the relative expression levels of RAD51 and BRCA2 in mouse cells transformed by the indicated oncoproteins. Numbers represents relative band intensity normalized to $\beta$-actin. (i) Colony-forming efficiency as an indicator of DSB repair is shown (left), as is the percentage of misrepair (right). Data are mean \pm s.e.m. of three independent experiments. One-way ANOVA was performed; ${ }^{*} P<0.05,{ }^{* *} P<0.001$. (j) Efficiency of HR-mediated repair of I-Scel-induced DSB in U2OS cells with a chromosomally integrated direct repeat-GFP reporter (U2OS-DR-GFP) transfected with I-Scel, dsRFP and the indicated oncoproteins or vector control. Data are mean \pm s.d. of three independent experiments. One-way ANOVA was performed; ${ }^{*} P<0.05,{ }^{* *} P<0.01$. 
and PML-RAR $\alpha$ mouse models (Fig. 3f). By analyzing the expression array data of these genes in two different human AML cohorts ${ }^{32,33}$, we consistently observed very similar suppression of these HR mediators in human AML1-ETO- and PML-RAR $\alpha$-associated leukemia, as compared with $M L L$-rearranged leukemia (Fig. 3g, Supplementary Fig. 3s and Supplementary Table 2). We also further validated the protein expression of key HR mediators, RAD51 and BRCA2, using mouse primary leukemic cells transformed by the corresponding fusions (Fig. 3h). To assess the direct effect of these fusions on DNA repair, we performed both a plasmid end-joining assay ${ }^{34}$ and an HR reporter assay ${ }^{35}$. Nuclear extracts from E2A-PBX- and MLL-AF9transformed cells could efficiently repair DSBs, and they produced significantly higher total numbers of colonies carrying the repaired plasmid than did AML1-ETO- and PML-RAR $\alpha$-transformed cells.
Moreover, in contrast to E2A-PBX- and MLL-AF9-transformed cells, most of the end repairs by nuclear extracts from AML1-ETO- or PMLRAR $\alpha$-transformed cells were mismatched (Fig. 3i). Consistently, we also observed significant suppression of HR efficiency upon expression of AML1-ETO or PML-RAR $\alpha$, as opposed to a small and significant increase in HR upon expression of MLL-AF9 (Fig. 3j). Therefore, these data indicate that leukemic cells driven by AML1-ETO and PML-RAR $\alpha$ had a reduced ability to repair DSB and that the repairs were accompanied by an increased error rate, which may form the basis for their increased PARPi sensitivity.

\section{Induction of HOXA9 by MLL fusions modulates PARPi sensitivity} In contrast to AML1-ETO and PML-RAR $\alpha^{20,24}$, MLL-fusion proteins recruit transactivation complexes culminating in expression of

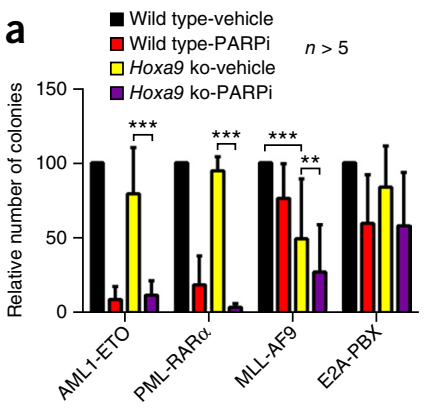

d

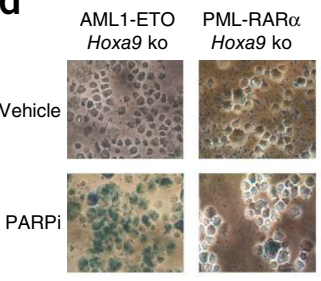

Figure 4 HOXA9 modulates sensitivity to PARPi.

(a) Relative colony number of primary transformed cells from wild-type or Hoxa9-/(Hoxa9 ko) background surviving after PARPi treatment. The number of colonies was normalized against the wild-type control. Data represents mean \pm s.d. of five independent experiments. Two-way ANOVA test was performed; ${ }^{*} P<0.01, * * * P<0.001$.

(b) Representative colony morphology of cells shown in a.

(c) May-Grunwald Giemsa staining of cells generated with Hoxa9-/- mice. (d) $\beta$-galactosidase staining of cells in $\mathbf{c}$.

(e) Quantification of percentage of $\beta$-galactosidase positive cells upon $48 \mathrm{~h}$ of PARPi treatment. Data are mean \pm s.d. of two independent experiments. Unpaired $t$-test was performed; ${ }^{*} P<0.05,{ }^{* * *} P<0.001$. (f,g) Kaplan-Meier survival curves of C57BI/6 mice transplanted with MLL-AF9 leukemic cells generated in wild-type (pooled from three independent experiments) (f) and Hoxa9-/- (pooled from three independent experiments) (g) backgrounds, respectively. (h) Relative number of colonies of primary transformed cells overexpressing HOXA9 in the presence of PARPi (left), and representative images of colony morphology (right). The number of colonies surviving to $7 \mathrm{~d}$ of incubation with PARPi was normalized against the vehicle control. Data are mean \pm s.d. of three independent experiments. Two-way ANOVA test was performed; ${ }^{* *} P<0.001$. (i) MayGrunwald Giemsa staining of primary transformed cells overexpressing HOXA9. (j) Representative $\beta$-galactosidase staining (left) and quantification of the percentage of $\beta$-galactosidase-positive cells upon PARPi treatment for 24 and $48 \mathrm{~h}$ (right). Data represents means of two independent experiments \pm s.d. One-way ANOVA test was performed; ${ }^{* *} P<0.001$.
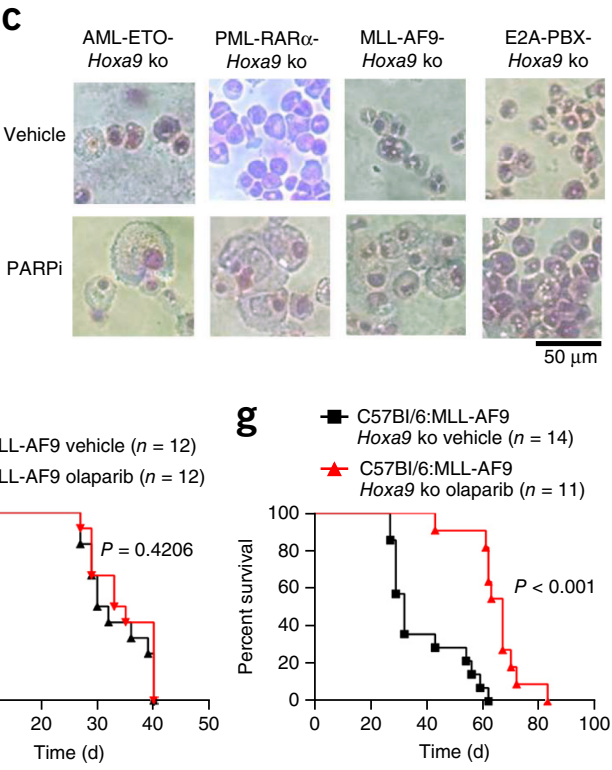

AML1-ETO PML-RAR $\alpha$ MLL-AF9 E2A-PBX HOXA9 HOXA9 HOXA9 HOXA9
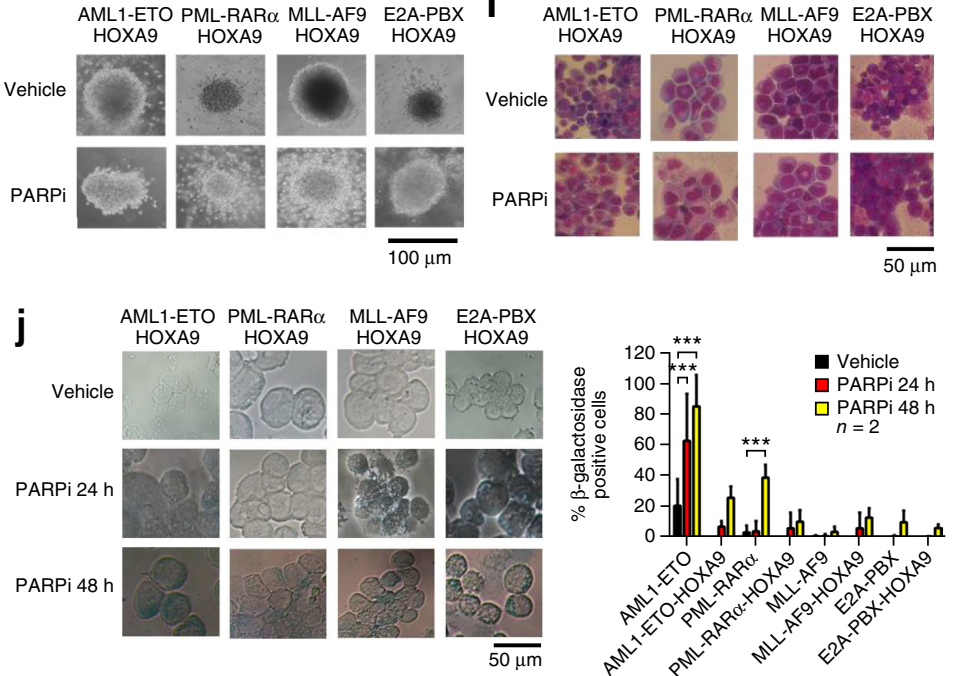
a
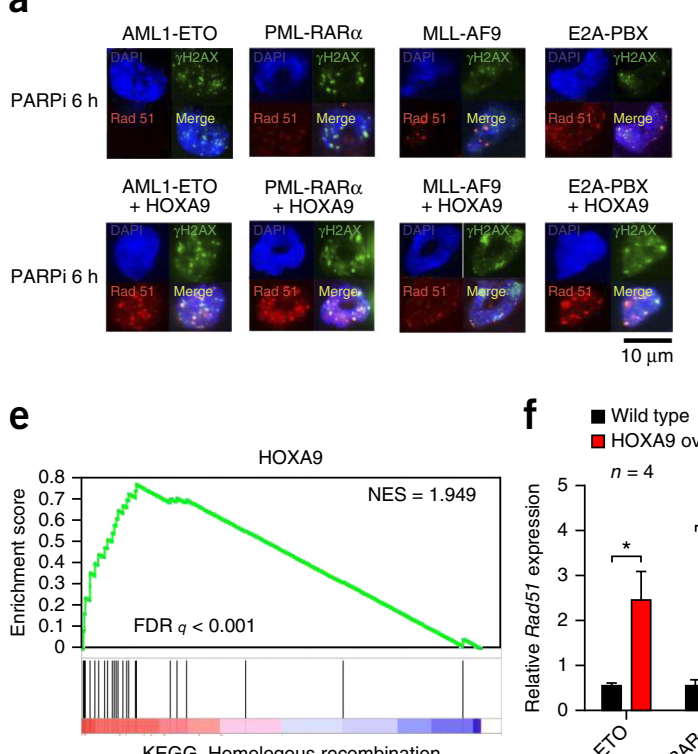

KEGG_Homologous recombination

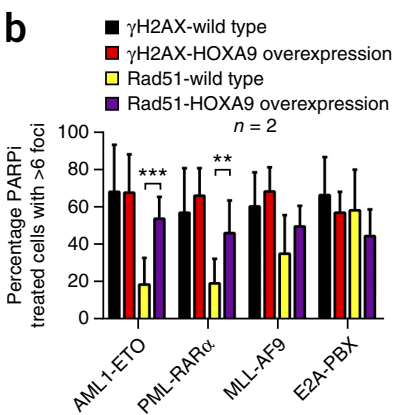

f Wild type

口 HOXA9 overexpression

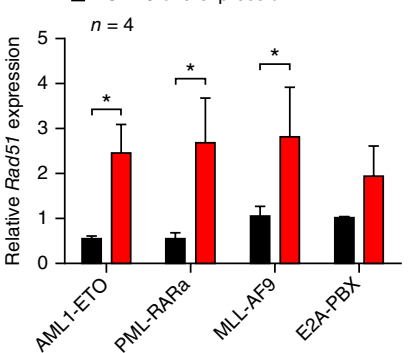

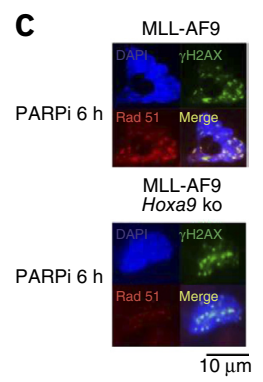
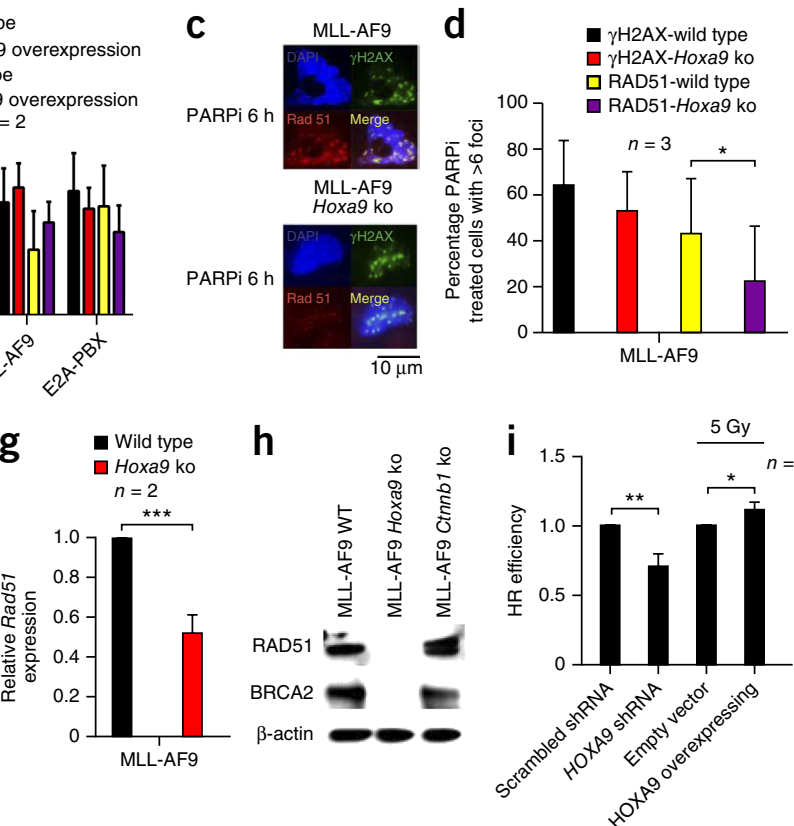
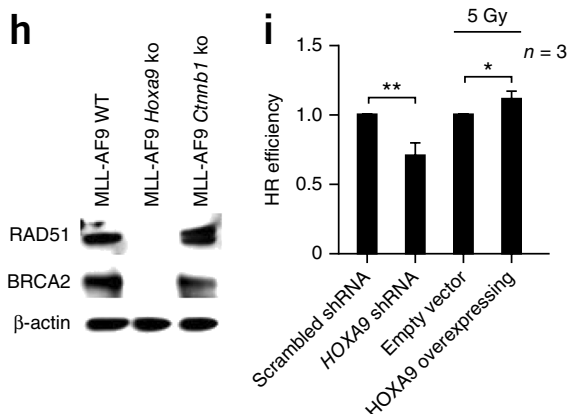

Figure 5 HOXA9 modulates PARPi sensitivity. (a) Immunofluorescence microscopy of PARPi induced $\gamma \mathrm{H} 2 \mathrm{AX}$ and RAD51 foci in wild-type and HOXA9-overexpressing cells (representative cells). (b) Quantification of the percentage of cells with $>6 \gamma \mathrm{H} 2 \mathrm{AX}$ or RAD51 foci in wild-type and HOXA9-overexpressing cells. Data are mean \pm s.d. Two-way ANOVA test was performed; ${ }^{*} P<0.01,{ }^{*} * P<0.001$. (c) Immunofluorescence microscopy of PARPi-induced $\gamma \mathrm{H} 2 \mathrm{AX}$ and RAD51 foci in MLL-AF9 cells generated in wild-type and Hoxa9-/- (Hoxa9 ko, Hoxa9 knockout) background (representative cells). (d) Quantification of percentage of cells with $>6 \gamma \mathrm{H} 2 \mathrm{AX}$ or RAD51 foci in wild-type and Hoxa9-/- cells. Data are mean \pm s.d. Two-way ANOVA test was performed; ${ }^{*}<0.05$. (e) Gene Set Enrichment Analysis (GSEA). Genes associated with homologous recombination pathway are enriched in the transcriptional profile of mouse myeloblasts overexpressing HOXA9. NES, normalized enrichment score; FDR, false discovery rate. (f) RT-qPCR showing expression levels of Rad51 in primary transformed mouse cells overexpressing HOXA9. Data are mean \pm s.d. Unpaired two-tailed $t$-test was performed; ${ }^{*} P<0.05$. (g) Relative expression of Rad51 in MLL-AF9-transformed cells generated in wild-type and Hoxa9-/- background. Data are mean \pm s.d. Unpaired two-tailed $t$-test was performed; ${ }^{* *} P<0.001$. (h) Western blot analysis of RAD51 and BRCA2 in MLL-AF9-transformed cells in wild-type, Hoxa9-/- and Ctnnb1 ${ }^{-/-}$background. $\beta$-actin was used as a loading control. (i) Bar chart shows efficiency of HR-mediated repair of I-Scel-induced DSBs in U2OS-DRGFP cells transfected with I-Scel, dsRFP, and HOXA9-expressing or HOXA9-targeting shRNA plasmids. Data is normalized to empty vector or scrambled shRNA. U20S-DRGFP cells were subject to 5 gray (Gy) radiation $24 \mathrm{~h}$ after HOXA9 overexpression. Unpaired $t$-test was performed; ${ }^{*} P<0.05,{ }^{* *} P<0.01$.

critical downstream genes, including the homeodomain transcription factor HOXA9 (refs. 20,36,37), which was previously identified as one of the single most critical independent prognostic factors associated with poor AML treatment response ${ }^{38}$, and the suppression of which has been linked to the drug-resistant phenotype in glioblastoma ${ }^{39,40}$. Consistently, we could observe specific and differential expression of Hoxa9 by MLL fusion in our mouse models and human samples (Supplementary Fig. 4a-c). Thus we hypothesized that the PARPi resistance exhibited by MLL-AF9-transformed cells might be dependent on the ability of MLL-AF9 to activate Hoxa9. To this end, we assessed the functional requirement of Hoxa9 in conferring PARPi resistance in MLL-AF9 cells using a Hoxa9-knockout mouse model. Consistent with previous reports ${ }^{24,41,42}$, knockout of Hoxa9 had a relatively modest effect on MLL-AF9-transformed cells despite a more mature phenotype and a slightly reduced colony-forming ability, as compared with their wild-type counterparts ${ }^{41}$ (Fig. 4a-c and Supplementary Fig. 4d-g). Notably, ablation of Hoxa9 expression sensitized MLL-AF9-transformed cells, but not HOXA9-independent E2A-PBX-transformed control cells ${ }^{24,43}$ to PARPi treatment, which resulted in a significant suppression of colony-forming ability but inductions of differentiation and senescence (Fig. 4a-e and Supplementary Fig. 4d-f). This is consistent with the role of Hoxa9 suppressing cellular senescence ${ }^{24}$, a common endpoint of excessive DNA damage. We then tested whether suppression of Hoxa9 sensitizes advanced-stage MLL leukemia to PARPi treatment in vivo by using MLL-AF9 full-blown leukemic cells harvested from primary transplanted mouse. As expected, olaparib did not have any significant effect on mice transplanted with wild-type MLL-AF9 leukemic cells. In contrast, although Hoxa9-deficient MLL-AF9 cells could efficiently induce leukemia, they were highly sensitive to PARPi treatment, which significantly delayed the disease latency (Fig. 4f,g and Supplementary Fig. 4h; Supplementary Tables 3 and 4). To further demonstrate the role of HOXA9 in mediating PARPi resistance, we also used a gain-of-function approach by overexpressing HOXA9 in PARPi-sensitive AML1-ETO- and PML-RAR $\alpha$-transformed cells. As expected, cells transduced with the vector control remained sensitive to PARPi. Forced expression of HOXA9 conferred PARPi resistance to AML1-ETO-and PML-RAR $\alpha$-transformed cells without affecting the expression of the fusions (Fig. $\mathbf{4 h}-\mathbf{j}$ and Supplementary Fig. $4 \mathbf{4}, \mathbf{j}$ ). Together with the loss-of-function data, these results strongly suggest Hoxa9 as a key player in mediating PARPi resistance.

\section{HOXA9 activates HR gene expression and DNA repair}

Upon HOXA9 overexpression, we observed significant recruitment of RAD51 to DNA damage foci in AML1-ETO- and PML-RAR $\alpha$ - but not E2A-PBX- or MLL-AF9-transformed cells, which already showed efficient recruitment of RAD51 (Fig. 5a-b). Conversely, suppression of Hoxa9 expression resulted in a significant impairment of RAD51 recruitment in MLL-AF9 transformed cells (Fig. 5c-d), leading to the hypothesis that HOXA9 might be an upstream regulator of RAD51. 
ARTICLES
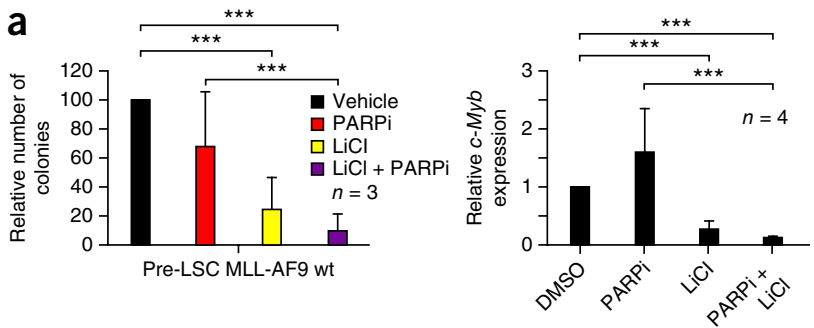

C
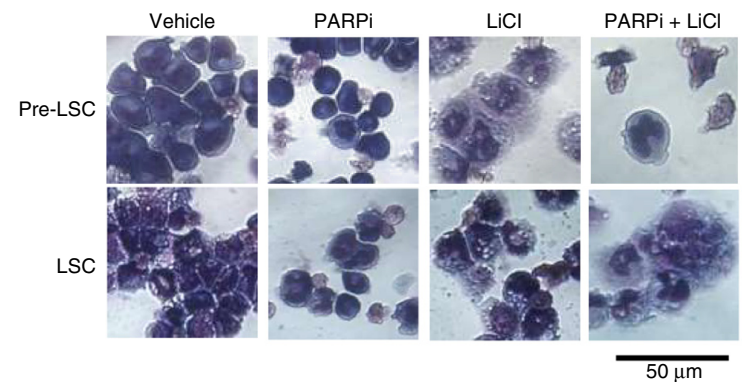

e

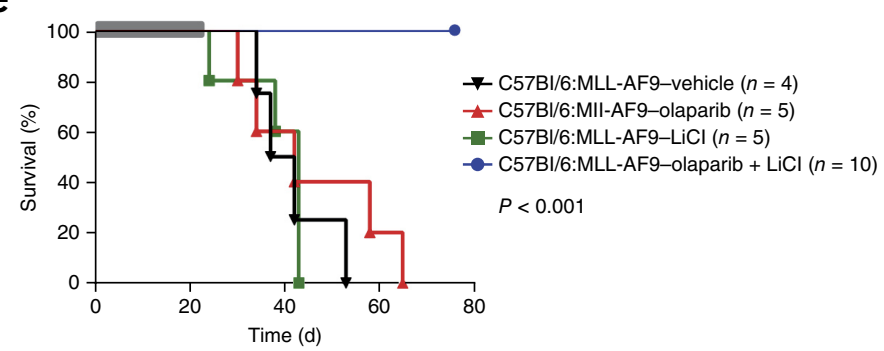

b
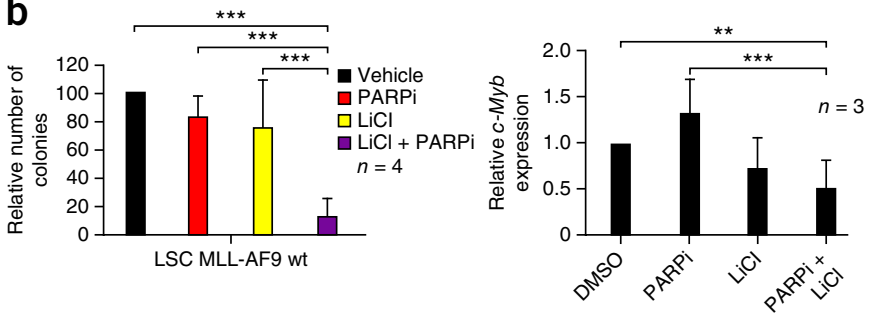

d
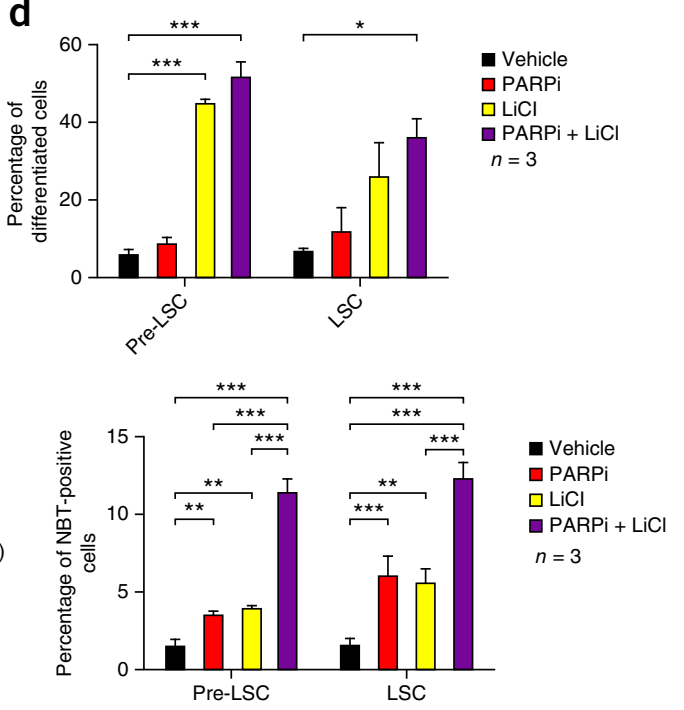

f

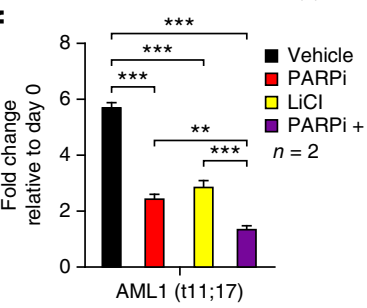

g

Vehicle

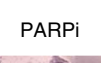

$\mathrm{LiCl}$

PARPi $+\mathbf{h}$

h
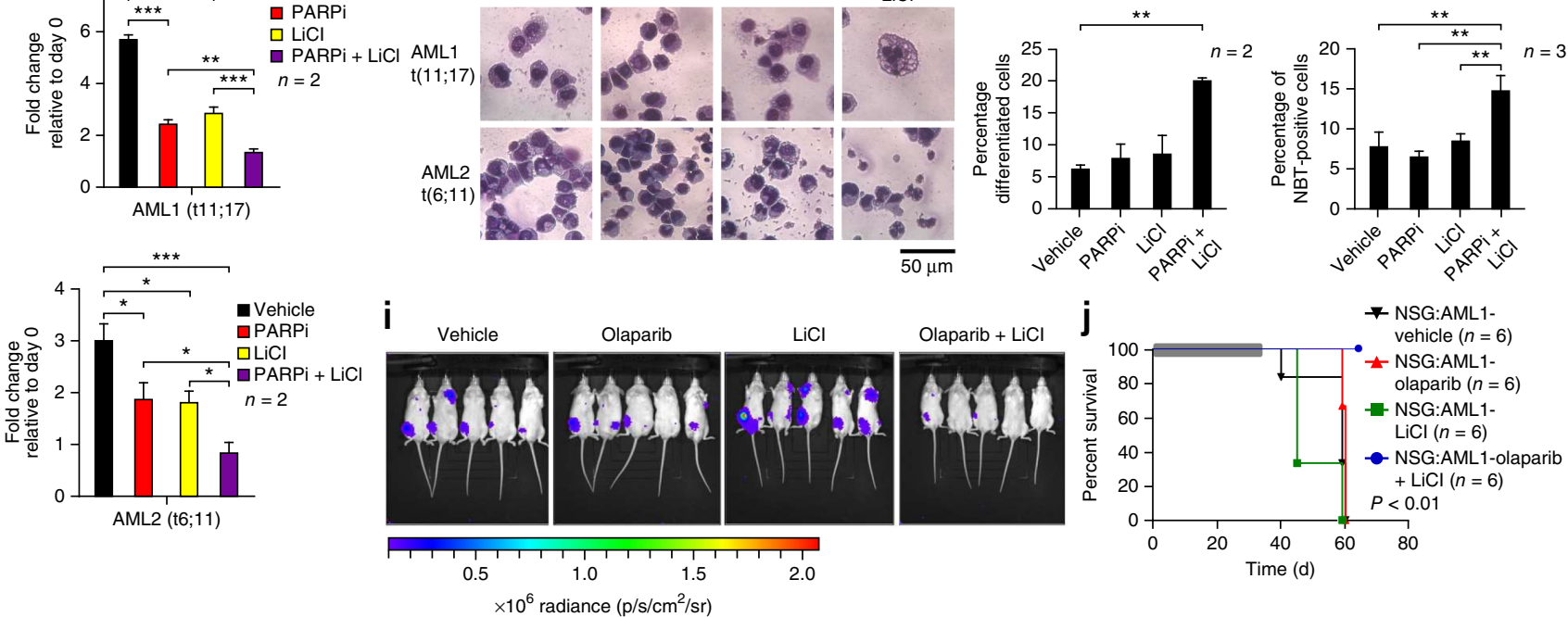

Figure 6 Combined PARPi and GSK3i treatment impairs in vivo survival of MLL leukemia cells. (a) Relative number of colonies (left) and $c-M y b$ expression (right) of pre-LSCs after treatment with DMSO, PARPi, LiCl or a combination of PARPi and LiCl. Data are mean \pm s.d. One-way ANOVA was performed; ${ }^{* * *} P<0.001$. wt, wild type. (b) Relative number of colonies (left) and $c-M y b$ expression (right) of LSCs after treatment with DMSO, PARPi, $\mathrm{LiCl}$ or a combination of PARPi and $\mathrm{LiCl}$. Data are mean \pm s.d. One-way ANOVA was performed; ${ }^{* *} P<0.01,{ }^{* *} P<0.001$. (c) May-Grunwald Giemsa staining of MLL-AF9 pre-LSCs and LSCs. (d) The percentage of pre-LSC and LSCs undergoing differentiation characterized by morphology (top) and nitro blue tetrazolium (NBT)-positive cells (bottom) after $4 \mathrm{~d}$ of treatment with vehicle (DMSO), PARPi, LiCl or a combination of PARPi and LiCl. Data are mean \pm s.d. One-way ANOVA was performed; ${ }^{*} P<0.05,{ }^{*} P<0.01,{ }^{* * *} P<0.001$. (e) Kaplan-Meier survival curves of C57BI/6 mice transplanted with MLL-AF9 LSCs pre-treated in liquid culture for $3 \mathrm{~d}$ before transplantation. Duration of in vivo treatment is indicated in gray. (f) Relative fold change in cell numbers of primary patients-derived leukemic cells carrying $M L L$-rearrangements [patient ID nos. AML1 (top) and AML2 (bottom)] after treatment with PARPi, LiCl, a combination of PARPi and $\mathrm{LiCl}$, or vehicle. Data are mean \pm s.d. One-way ANOVA test was performed; ${ }^{*} P<0.05$; ${ }^{* *} P<0.01 ;{ }^{* *} P<0.001$. (g) May-Grunwald Giemsa staining of human MLL samples. (h) The percentage of primary leukemic cells undergoing differentiation characterized by morphology (left) and by NBT-positive cells (right). Data are mean \pm s.d. One-way ANOVA was performed; ** $P<0.01$. (i) Images showing the tumor burden of NSG mice transplanted with primary patient-derived leukemic cells carrying $M L L$-rearrangement after treatment with vehicle (DMSO), olaparib, $\mathrm{Li}_{2} \mathrm{CO}_{3}$ or a combination of olaparib and $\mathrm{Li}_{2} \mathrm{CO}_{3}$. (j) Kaplan-Meier survival curves of NSG mice transplanted with primary patient-derived leukemic cells carrying MLL-rearrangements (patient ID no. AML1). Duration of in vivo treatment is indicated in gray. 
To this end, we analyzed the expression array data of known HOXA9 downstream targets in primary transformed myeloid cells ${ }^{44,45}$. This revealed that genes involved in DNA repair were significantly enriched in HOXA9-responsive gene sets (Fig. 5e, Supplementary Fig. 5a,b and Supplementary Table 2), which was also confirmed by RT-qPCR using wild-type and Hoxa9-knockout MLL-AF9-transformed cells (Supplementary Fig. 5c). Among them were key HR-related genes including Rad51 (refs. 12,30,31), a fact that was further validated in the primary transformed cells by both HOXA9 -overexpression (Fig. 5f) and Hoxa9-knockout approaches (Fig. 5g and Supplementary Fig. 5d). Consistently, the expression of RAD51 and BRCA2 proteins were significantly diminished in the absence of Hoxa9 (but not Ctnnb1 $1^{-/-}$ control) (Fig. 5h). Finally, to demonstrate a direct involvement of HOXA9 in DDR, HR-reporter assays further revealed enhanced HR efficiency by HOXA9 overexpression as opposite to a compromised HR response with HOXA9 suppression (Fig. 5i). These data strongly suggest that HOXA9 confers PARPi-resistance in part by activating DDR transcriptional programs.

\section{Targeting PARPi-resistant AML with a combination approach}

Although there is not yet a chemical inhibitor that can directly target HOXA9, inhibitors are available to suppress its regulators and essential co-factors, including GSK3, which mediates the phosphorylation of CREBBP (CREB binding protein, also known as CBP), which is required for HOX transcriptional functions ${ }^{46}$. We and others have previously shown that GSK3 inhibitors (GSKis), such as $\mathrm{LiCl}$ and $\mathrm{Li}_{2} \mathrm{CO}_{3}$, were effective in suppressing the transcriptional activity of HOXA9 and targeting MLL pre-leukemic stem cells (pre-LSCs), but not the advanced-stage MLL-LSCs that acquired resistance in part because of the activation of canonical Wnt/ $\beta$-catenin pathways, and which were capable of inducing leukemia with a much shorter latency ${ }^{23,46,47}$. To further explore the potential application of PARPi on MLL leukemia, we assessed the effect of PARPi in combination with GSK3i, on both MLL pre-LSC- and MLL-LSC-enriched populations that exhibited contrasting GSKi sensitivity and disease latency ${ }^{23}$. As expected, the application of a previously-defined optimal concentration of $\mathrm{LiCl}$ (refs. 23,46,47) significantly suppressed the colony-forming ability of MLL pre-LSCs, but not MLL-LSCs (Fig. 6a,b and Supplementary Fig. 6a-c). Notably, combining LiCl with PARPi led to further inhibition of MLL pre-LSCs, which inversely correlated with transcriptional activity of HOXA9 as assessed by the expression of its downstream target, $c-M y b$ (Fig. 6a-b). Of further note, whereas individual PARPi or $\mathrm{LiCl}$ treatment was ineffective on MLL-LSCs, the combination of the two treatments dramatically suppressed growth and induced differentiation of MLL-LSCs (Fig. 6b-d). To further demonstrate the in vivo efficacy, pretreated MLL-LSCs were transplanted into syngeneic mice and subjected to treatment with olaparib, $\mathrm{Li}_{2} \mathrm{CO}_{3}$, or the combination of the two. As expected, mice transplanted with control MLLAF9 cells succumbed to leukemia within 8 weeks. PARPi or GSK3i treatment alone did not significantly extend the survival; notably, the combined PARPi and GSK3i treatment suppressed leukemia development, and all the mice survived throughout the experiment (Fig. 6e, Supplementary Fig. 6d,e, and Supplementary Table 5).

To investigate whether a similar treatment could also be effective in the corresponding human leukemia, we first used THP1 cells that were mostly refractory to olaparib and showed little effect when treated with $\mathrm{LiCl}$. However in combination, $\mathrm{LiCl}$ could sensitize PARPiresistant THP1 cells to the PARPi treatment, resulting in significant growth suppression and differentiation (Supplementary Fig. 6f,g). Then we performed the same treatments on two independent primary human AML samples carrying MLL-fusions (i.e., patient ID nos. AML1 and AML2). Whereas limited inhibition resulted from individual treatments, combination treatments showed consistent synergistic effects in suppressing growth and promoting differentiation of primary MLL leukemic cells from both patients (Fig. 6f-h). Finally, to further demonstrate the in vivo treatment efficacy, we labeled cells from patient AML1 with a luciferase reporter prior to their transplantation into NSG mice for drug treatment. By in vivo imaging, we observed a rapid disease development as early as 4 weeks after transplant in the untreated control. We observed a similar rate of disease progression in cohorts receiving single-drug treatments, although the $\mathrm{Li}_{2} \mathrm{CO}_{3}$-treated group exhibited an even faster rate of leukemic growth (Fig. 6i and Supplementary Fig. 6h). In contrast, $\mathrm{PARPi}$ and $\mathrm{Li}_{2} \mathrm{CO}_{3}$ combination treatment significantly prohibited leukemic growth in vivo (Fig. 6i and Supplementary Fig. 6h). After long-term disease development, mice that received single-drug treatments succumbed to leukemia with a similar phenotype and disease latency as the control group. Notably, the combination treatment significantly suppressed leukemia development, and none of the mice treated with combination therapy succumbed to leukemia throughout the observation period (Fig. 6j, Supplementary Fig. 6i,j and Supplementary Table 6). Together, these independent results from mouse and primary human xenograft models provide the first proof-of-principle pre-clinical evidence for a novel effective therapeutic strategy based on a combined PARPi and GSK3i treatment for MLL leukemia.

\section{DISCUSSION}

In spite of the lack of genetic mutations directly affecting DDR-associated genes, we provide molecular and preclinical data showing the potential utility of PARPi-mediated selective killing of leukemic cells carrying specific oncogenic transcription factors (Supplementary Fig. 7). In addition to the discovery of strong PARPi sensitivity in leukemic cells driven by AML1-ETO and PML-RAR $\alpha$, which suppress DDR ${ }^{48-52}$, we also demonstrate for the first time that HOXA9, an independent poor prognostic factor in $\mathrm{AML}^{38}$ and a key downstream target of MLL-fusions ${ }^{53}$, can activate DDR pathways and allow leukemia cells to overcome PARPis. This finding may also in part explain the previously reported S-phase checkpoint dysfunction of MLL-rearranged cells that show radio-resistant DNA synthesis and chromatid-type genomic abnormalities ${ }^{54}$. Emerging evidence suggests that various HOX proteins may be involved in DNA repair ${ }^{55,56}$. HOXB7 interacts with PARP-1 and the DNA-PK-Ku80-Ku70 complex-enabling NHEJ pathway ${ }^{55}$, whereas HOXB9 promotes HR by inducing TGF- $\beta$, which in turn enhances ataxia telangiectasia-mutated (ATM) activation and ATM-dependent response in breast cancer cell lines ${ }^{56}$. Our data indicate that HOXA9 mediates expression of critical DDR-related genes to stimulate an HR response to PARPi treatment. Consistent with its putative role in mediating drug-resistance in glioma ${ }^{43,44}$, we further demonstrate that HOXA9 overexpression rescues AML1ETO- and PML-RAR $\alpha$-transformed cells from PARPi treatment, whereas HOXA9 suppression makes MLL-AF9-transformed cells sensitive to PARPi, revealing a novel function of HOXA9 in governing PARPi resistance in AML.

In line with a classical model of DDR barrier in cancer development ${ }^{57}$, a recent study by Takacova et al. ${ }^{58}$ demonstrated that inactivation of the DDR barrier through ATM and ataxia telangiectasia and Rad3-related (ATR) inhibitors accelerated leukemia driven by a tamoxifen-inducible MLL-fusion ${ }^{58}$. In contrast, Santos et al. ${ }^{59}$ have elegantly shown that genetic ablation of critical DDR-associated 
genes such as MLL4, ATM or BRCA1, instead of accelerating MLLdriven leukemogenesis, induced leukemic differentiation. These results suggest dual roles of the key DDR players, such as ATM, in promoting and suppressing MLL-leukemia, which may be dosage and context dependent. Notably, HOXA9, which drives leukemic growth and PARPi resistance, is largely dispensable for normal development ${ }^{24,42,60}$, highlighting its potential as a therapeutic target. As a proof of principle, we further demonstrate that the combined use of PARPi together with GSK3i, which targets the transcriptional function of HOXA9 (refs. 23,46,47), can achieve selective killing of otherwise PARPi-resistant MLL leukemia, revealing a novel venue for overcoming PARPi resistance in leukemia (Supplementary Fig. 7).

\section{METHODS}

Methods and any associated references are available in the online version of the paper.

Note: Any Supplementary Information and Source Data files are available in the online version of the paper.

\section{ACKNOWLEDGMENTS}

We thank G. Mufti, S. Shall, T. Ng, and D. Weekes for insightful discussion; A. Zelent (Miller School of Medicine, University of Miami), M. Greaves (The Institute of Cancer Research, London ) and O. Heidenreich (Northern Institute for Cancer Research, Newcastle University) for providing NB4-LR2, THP1 and Kasumi cell lines, respectively; I. Ahel (Sir William Dunn School of Pathology, University of Oxford), I. Gibbs-Seymour (Sir William Dunn School of Pathology, University of Oxford), and D. Livingston (Dana-Farber Cancer Institute, Harvard University) for tagged ALPF and PARP1 constructs; E. Soutoglou (Institut de Genetique de Biologie Moleculaire et Celluraire) and M. Jasin (Memorial Sloan Kettering Cancer Center) for DR-GFP HR reporter systems; H. Lee (School of Biological Sciences, Seoul National University) and M. Tarsounas (Oxford University for Radiation Oncology) for BRCA2-specific antibody; J. Hess (Department of Pathology, University of Michigan School of Medicine) for the MSCV-HA-Hoxa9-IRES-GFP construct; C. Lourenco and W. Vetharoy for technical assistance with mice experiments and FACS analysis; S. Tung, A. Innes and P. Lau for technical assistance with gene expression profiling; T. Gaymes for support with DNA damage repair experiments; and P. Tse for graphical illustration. This work was supported by program grants from Bloodwise and Cancer Research UK (to C.W.E.S.).

\section{AUTHOR CONTRIBUTIONS}

M.T.E., L.Z. T.K.F. and J.K.R. performed experiments and analyzed the data. A.W. provided technical support for the in vivo experiments. N.M. and J.G. performed mass spectrometry and data analysis. A.Y.L. and A.A. provide essential reagents and data interpretation. M.T.E and C.W.E.S. wrote the manuscript. C.W.E.S. conceptualized, designed and supervised the study.

\section{COMPETING FINANCIAL INTERESTS}

The authors declare competing financial interests: details are available in the online version of the paper.

Reprints and permissions information is available online at http://www.nature.com/ reprints/index.html.

1. Krishnakumar, R. \& Kraus, W.L. The PARP side of the nucleus: molecular actions, physiological outcomes, and clinical targets. Mol. Cell 39, 8-24 (2010).

2. McLornan, D.P., List, A. \& Mufti, G.J. Applying synthetic lethality for the selective targeting of cancer. N. Engl. J. Med. 371, 1725-1735 (2014).

3. De Lorenzo, S.B., Patel, A.G., Hurley, R.M. \& Kaufmann, S.H. The elephant and the blind men: making sense of PARP inhibitors in homologous recombinationdeficient tumor cells. Front. Oncol. 3, 228 (2013).

4. Helleday, T. The underlying mechanism for the PARP and BRCA synthetic lethality: clearing up the misunderstandings. Mol. Oncol. 5, 387-393 (2011).

5. El-Khamisy, S.F., Masutani, M., Suzuki, H. \& Caldecott, K.W. A requirement for PARP-1 for the assembly or stability of XRCC1 nuclear foci at sites of oxidative DNA damage. Nucleic Acids Res. 31, 5526-5533 (2003).

6. Masson, M. et al. XRCC1 is specifically associated with poly(ADP-ribose) polymerase and negatively regulates its activity following DNA damage. Mol. Cell. Biol. 18, 3563-3571 (1998).

7. Bryant, H.E. et al. PARP is activated at stalled forks to mediate Mre11-dependent replication restart and recombination. EMBO J. 28, 2601-2615 (2009).
8. Haince, J.F. et al. PARP1-dependent kinetics of recruitment of MRE11 and NBS1 proteins to multiple DNA damage sites. J. Biol. Chem. 283, 1197-1208 (2008).

9. Haince, J.F. et al. Ataxia telangiectasia mutated (ATM) signaling network is modulated by a novel poly(ADP-ribose)-dependent pathway in the early response to DNA-damaging agents. J. Biol. Chem. 282, 16441-16453 (2007).

10. Paddock, M.N. et al. Competition between PARP-1 and Ku70 control the decision between high-fidelity and mutagenic DNA repair. DNA Repair (Amst.) 10, 338-343 (2011).

11. Roy, R., Chun, J. \& Powell, S.N. BRCA1 and BRCA2: different roles in a common pathway of genome protection. Nat. Rev. Cancer 12, 68-78 (2012).

12. Carreira, A. et al. The BRC repeats of BRCA2 modulate the DNA-binding selectivity of RAD51. Cell 136, 1032-1043 (2009).

13. Fong, P.C. et al. Inhibition of poly(ADP-ribose) polymerase in tumors from BRCA mutation carriers. N. Engl. J. Med. 361, 123-134 (2009).

14. Tutt, A. et al. Oral poly(ADP-ribose) polymerase inhibitor olaparib in patients with $B R C A 1$ or BRCA2 mutations and advanced breast cancer: a proof-of-concept trial. Lancet 376, 235-244 (2010).

15. Bryant, H.E. et al. Specific killing of BRCA2-deficient tumours with inhibitors of poly(ADP-ribose) polymerase. Nature 434, 913-917 (2005)

16. Farmer, H. et al. Targeting the DNA repair defect in BRCA mutant cells as a therapeutic strategy. Nature 434, 917-921 (2005).

17. Helleday, T., Petermann, E., Lundin, C., Hodgson, B. \& Sharma, R.A. DNA repair pathways as targets for cancer therapy. Nat. Rev. Cancer 8, 193-204 (2008).

18. Kraus, W.L. Transcriptional control by PARP-1: chromatin modulation, enhancerbinding, coregulation, and insulation. Curr. Opin. Cell Biol. 20, 294-302 (2008).

19. Esposito, M.T. \& So, C.W. DNA damage accumulation and repair defects in acute myeloid leukemia: implications for pathogenesis, disease progression, and chemotherapy resistance. Chromosoma 123, 545-561 (2014).

20. Cheung, N. \& So, C.W. Transcriptional and epigenetic networks in haematological malignancy. FEBS Lett. 585, 2100-2111 (2011).

21. Zeisig, B.B., Kulasekararaj, A.G., Mufti, G.J. \& So, C.W. Acute myeloid leukemia: snapshot. Cancer Cell 22, 698 (2012).

22. Zeisig, B.B. \& So, C.W. Retroviral/lentiviral transduction and transformation assay. Methods Mol. Biol. 538, 207-229 (2009).

23. Yeung, J. et al. $\beta$-Catenin mediates the establishment and drug resistance of MLL leukemic stem cells. Cancer Cell 18, 606-618 (2010).

24. Smith, L.L. et al. Functional crosstalk between Bmi1 and MLL/Hoxa9 axis in establishment of normal hematopoietic and leukemic stem cells. Cell Stem Cell 8 , 649-662 (2011).

25. Arteaga, M.F. et al. The histone demethylase PHF8 governs retinoic acid response in acute promyelocytic leukemia. Cancer Cell 23, 376-389 (2013).

26. Fung, T.K. \& So, C.W. Overcoming treatment resistance in acute promyelocytic leukemia and beyond. Oncotarget 4, 1128-1129 (2013).

27. Santos, M.A. et al. DNA-damage-induced differentiation of leukaemic cells as an anti-cancer barrier. Nature 514, 107-111 (2014).

28. Turner, N., Tutt, A. \& Ashworth, A. Hallmarks of 'BRCAness' in sporadic cancers Nat. Rev. Cancer 4, 814-819 (2004).

29. Mah, L.J., El-Osta, A. \& Karagiannis, T.C. $\gamma \mathrm{H} 2 \mathrm{AX}$ : a sensitive molecular marker of DNA damage and repair. Leukemia 24, 679-686 (2010).

30. Baumann, P., Benson, F.E. \& West, S.C. Human Rad51 protein promotes ATP-dependent homologous pairing and strand transfer reactions in vitro. Cell $\mathbf{8 7}$, 757-766 (1996)

31. Moynahan, M.E. \& Jasin, M. Mitotic homologous recombination maintains genomic stability and suppresses tumorigenesis. Nat. Rev. Mol. Cell Biol. 11, 196-207 (2010).

32. Valk, P.J. et al. Prognostically useful gene-expression profiles in acute myeloid leukemia. N. Engl. J. Med. 350, 1617-1628 (2004).

33. Verhaak, R.G. et al. Prediction of molecular subtypes in acute myeloid leukemia based on gene expression profiling. Haematologica 94, 131-134 (2009).

34. Gaymes, T.J., Mufti, G.J. \& Rassool, F.V. Myeloid leukemias have increased activity of the nonhomologous end-joining pathway and concomitant DNA misrepair that is dependent on the Ku70/86 heterodimer. Cancer Res. 62, 2791-2797 (2002).

35. Pierce, A.J., Johnson, R.D., Thompson, L.H. \& Jasin, M. XRCC3 promotes homologydirected repair of DNA damage in mammalian cells. Genes Dev. 13, 2633-2638 (1999).

36. Yip, B.H. \& So, C.W. Mixed-lineage leukemia protein in normal and leukemic stem cells. Exp. Biol. Med. (Maywood) 238, 315-323 (2013).

37. Krivtsov, A.V. \& Armstrong, S.A. MLL translocations, histone modifications and leukaemia stem-cell development. Nat. Rev. Cancer 7, 823-833 (2007).

38. Golub, T.R. et al. Molecular classification of cancer: class discovery and class prediction by gene expression monitoring. Science 286, 531-537 (1999).

39. Costa, B.M. et al. Reversing HOXA9 oncogene activation by PI3K inhibition: epigenetic mechanism and prognostic significance in human glioblastoma. Cance Res. 70, 453-462 (2010).

40. Gaspar, N. et al. MGMT-independent temozolomide resistance in pediatric glioblastoma cells associated with a PI3-kinase-mediated HOX/stem cell gene signature. Cancer Res. 70, 9243-9252 (2010).

41. Kumar, A.R. et al. Hoxa9 influences the phenotype but not the incidence of MII-AFS fusion gene leukemia. Blood 103, 1823-1828 (2004).

42. So, C.W., Karsunky, H., Wong, P., Weissman, I.L. \& Cleary, M.L. Leukemic transformation of hematopoietic progenitors by MLL-GAS7 in the absence of Hoxa7 or Hoxa9. Blood 103, 3192-3199 (2004). 


\section{ARTICLES}

43. So, C.W. et al. MLL-GAS7 transforms multipotent hematopoietic progenitors and induces mixed lineage leukemias in mice. Cancer Cell 3, 161-171 (2003).

44. Faber, J. et al. HOXA9 is required for survival in human MLL-rearranged acute leukemias. Blood 113, 2375-2385 (2009).

45. Huang, Y. et al. Identification and characterization of Hoxa9 binding sites in hematopoietic cells. Blood 119, 388-398 (2012).

46. Wang, Z. et al. GSK-3 promotes conditional association of CREB and its coactivators with MEIS1 to facilitate HOX-mediated transcription and oncogenesis. Cancer Cell 17, 597-608 (2010).

47. Wang, Z. et al. Glycogen synthase kinase 3 in MLL leukaemia maintenance and targeted therapy. Nature 455, 1205-1209 (2008).

48. Viale, A. et al. Cell-cycle restriction limits DNA damage and maintains self-renewal of leukaemia stem cells. Nature 457, 51-56 (2009).

49. Boichuk, S., Hu, L., Makielski, K., Pandolfi, P.P. \& Gjoerup, O.V. Functional connection between Rad51 and PML in homology-directed repair. PLOS ONE 6, e25814 (2011).

50. Yeung, P.L. et al. Promyelocytic leukemia nuclear bodies support a late step in DNA double-strand break repair by homologous recombination. J. Cell. Biochem. 113, 1787-1799 (2012)

51. Zhong, S. et al. A role for PML and the nuclear body in genomic stability. Oncogene 18, 7941-7947 (1999).
52. Alcalay, M. et al. Acute myeloid leukemia fusion proteins deregulate genes involved in stem cell maintenance and DNA repair. J. Clin. Invest. 112, 1751-1761 (2003).

53. Armstrong, S.A. et al. $M L L$ translocations specify a distinct gene expression profile that distinguishes a unique leukemia. Nat. Genet. 30, 41-47 (2002).

54. Liu, H. et al. Phosphorylation of MLL by ATR is required for execution of mammalian S-phase checkpoint. Nature 467, 343-346 (2010)

55. Rubin, E. et al. A role for the HOXB7 homeodomain protein in DNA repair. Cance Res. 67, 1527-1535 (2007).

56. Chiba, N. et al. Homeobox B9 induces epithelial-to-mesenchymal transitionassociated radioresistance by accelerating DNA damage responses. Proc. Natl. Acad. Sci. USA 109, 2760-2765 (2012)

57. Blanpain, C., Mohrin, M., Sotiropoulou, P.A. \& Passegue, E. DNA-damage response in tissue-specific and cancer stem cells. Cell Stem Cell 8, 16-29 (2011).

58. Takacova, S. et al. DNA damage response and inflammatory signaling limit the MLL-ENL-induced leukemogenesis in vivo. Cancer Cell 21, 517-531 (2012).

59. Santos, M.A. et al. DNA-damage-induced differentiation of leukaemic cells as an anti-cancer barrier. Nature 514, 107-111 (2014).

60. Lawrence, H.J. et al. Loss of expression of the Hoxa-9 homeobox gene impairs the proliferation and repopulating ability of hematopoietic stem cells. Blood 106 3988-3994 (2005). 


\section{ONLINE METHODS}

Retroviral transduction/transformation assay (RTTA). RTTA was performed on primary mouse hematopoietic cells as described ${ }^{22}$. c-Kit-positive progenitor cells were isolated from wild-type Ly5.1 mouse bone marrow, and cultured overnight in R10 medium (RPMI 1640 containing 10\% FCS, $100 \mathrm{U} / \mathrm{ml}$ penicillin and $100 \mu \mathrm{g} / \mathrm{mL}$ streptomycin) supplemented with $20 \mathrm{ng} / \mathrm{ml}$ stem cell factor (SCF), $10 \mathrm{ng} / \mathrm{ml}$ interleukin (IL)-3, and 10ng/ml IL-6. Transduction using concentrated viral supernatant expressing the oncogene of interest was carried out by centrifugation (spinoculation) at $800 \mathrm{~g}$ at $32^{\circ} \mathrm{C}$ for $2 \mathrm{~h}$ in the presence of $5 \mu \mathrm{g} / \mathrm{ml}$ polybrene (Sigma-Aldrich). Cells were subsequently plated in $1 \%$ methylcellulose medium (M3231; Stem Cell Technologies) containing $20 \mathrm{ng} / \mathrm{ml}$ SCF, $10 \mathrm{ng} / \mathrm{ml} \mathrm{IL-3,} 10 \mathrm{ng} / \mathrm{ml} \mathrm{IL}-6$ and $10 \mathrm{ng} / \mathrm{ml}$ granulocyte macrophage colony-stimulating factor (GM-CSF) and appropriate selection antibiotic. Colonies were counted after $7 \mathrm{~d}$ of culture and re-plated every $6-7 \mathrm{~d}$ at $5 \times 10^{3}$ $1.5 \times 10^{4}$ cell density. Re-plating was performed weekly to generate primary cell lines for further analysis. After the third or fourth round of plating, cells were cultured in R20/20 medium (RPMI 1640, 20\% FCS, 20\% WEHI-conditioned medium, $2 \mathrm{mM}$ L-glutamine, $100 \mathrm{U} / \mathrm{ml}$ penicillin, and $100 \mu \mathrm{g} / \mathrm{ml}$ streptomycin) supplemented with $20 \mathrm{ng} / \mathrm{ml} \mathrm{SCF}, 10 \mathrm{ng} / \mathrm{ml} \mathrm{IL}-3$, and $10 \mathrm{ng} / \mathrm{ml} \mathrm{IL-} 6$ to establish cell lines. All recombinant mouse cytokines were from Peprotech.

Cell culture. NB4-LR2 and THP1 cell lines were cultured in RPMI (Invitrogen) supplemented with $10 \%$ selected FBS (R10), 2 mM L-glutamine. The Kasumi cell line was cultured in RPMI-HEPES modified (Sigma) supplemented with $20 \%$ selected FBS and $2 \mathrm{mM}$ L-glutamine (R20). Cell lines were validated by qPCR for their respective oncogenes. NIH3T3 and GP2 cell line was cultured in DMEM (Invitrogen) supplemented with $10 \%$ selected FBS and $2 \mathrm{mM}$ L-glutamine. Human primary AML cells were cultured in IMEM (Invitrogen) supplemented with $10 \%$ PBS, $2 \mathrm{mM}$ L-glutamine, $10 \mathrm{ng} / \mathrm{ml}$ each of the human cytokines IL3, IL6, SCF, FLT3 ligand, and TPO. Cells were kept at $37{ }^{\circ} \mathrm{C}$ and $5 \% \mathrm{CO}_{2}$. Use of human primary cells was approved by King's College London's local ethics committee and patient consent was obtained.

In vitro drug treatment. Most of the inhibitor studies on mouse cells were carried out by plating $3-5 \times 10^{3}$ cells in $1 \%$ methylcellulose medium containing $20 \mathrm{ng} / \mathrm{ml} \mathrm{SCF}, 10 \mathrm{ng} / \mathrm{ml} \mathrm{IL}-3,10 \mathrm{ng} / \mathrm{ml} \mathrm{IL-} 6$ and $10 \mathrm{ng} / \mathrm{ml}$ GM-CSF in the presence of $1 \mu \mathrm{M}$ olaparib (LC Laboratories), $1 \mu \mathrm{M}$ veliparib (Abbott) or $8 \mathrm{mM}$ $\mathrm{LiCl}$ (Sigma) at the concentrations as indicated in the Results section. Colonies were scored 6-7 d after plating. For other in vitro studies, mouse leukemic cells and primary AML cell lines were subjected to continuous olaparib $(1 \mu \mathrm{M})$ or $\mathrm{LiCl}(8 \mathrm{mM})$ treatment in liquid culture for the duration as indicated in the figures or figure legends. For human leukemic cell lines, experiments were performed as described above with $5 \mu \mathrm{M}$ olaparib.

Flow cytometric analysis. Flow cytometry analyses of mouse leukemic cells for both in vitro and in vivo experiments were performed as previously described ${ }^{61}$ using mouse-specific anti-CD11b (Mac-1,clone M1/70), anti-Gr1 (clone RB6-8C5), anti-c-Kit (clone 2B8), anti-CD45.1 (clone A20) and anti-CD45.2 (clone 104) antibodies from BioLegend. For humanized mouse model, the engrafted human donor cells were analyzed using anti-human CD45 (clone H130) and CD33 (clone WM53). All antibodies are used at a dilution of 1:200.

Cell cycle analysis. For each assay, $10^{5}$ cells were collected, washed in PBS and fixed in $70 \%$ cold ethanol. After re-hydration with PBS and centrifugation at $500 \mathrm{~g}$ for $5 \mathrm{~min}$, the cells were incubated with a solution of PBS containing $1 \%$ FCS, $40 \mu \mathrm{g} / \mathrm{ml}$ RNase and $500 \mu \mathrm{g} / \mathrm{ml}$ propidium iodide solution (Sigma-Aldrich) in the dark for $30 \mathrm{~min}$ at $37^{\circ} \mathrm{C}$. Samples were then analyzed at the FACS LSRII (BD Biosciences). DNA peaks were analyzed with FACS Diva software (BD Biosciences).

Annexin V staining. For each assay, $10^{5}$ cells were collected, washed in PBS and re-suspended in annexin $\mathrm{V}$ binding solution (25 mM HEPES, $140 \mathrm{mM} \mathrm{KCl}, 2.5 \mathrm{mM}$ $\mathrm{CaCl}_{2}, \mathrm{pH}$ 7.2). After centrifugation at $500 \mathrm{~g}$ for $5 \mathrm{~min}$, the cells were incubated with the annexin $\mathrm{V}$ binding solution containing $0.25 \mu \mathrm{g} / \mathrm{ml}$ mouse anti-annexin V-FITC (BioLegend, 640906) and $1 \mu \mathrm{g} / \mathrm{ml}$ propidium iodide (Sigma) in the dark for $30 \mathrm{~min}$ at $4{ }^{\circ} \mathrm{C}$. Samples were then washed in PBS and analyzed with the FACS LSRII (BD Biosciences) with FACS Diva software (BD Biosciences).
$\boldsymbol{\beta}$-Galactosidase staining. Cells were cytospun onto a glass slide at $400 \mathrm{~g}$ for $5 \mathrm{~min}$ and then fixed for 10 min with $2 \%$ formaldehyde and $0.2 \%$ glutaraldehyde (Sigma-Aldrich). Cells were then washed with PBS, and then incubated at $37^{\circ} \mathrm{C}$ for at least $2 \mathrm{~h}$ with a staining solution $(30 \mathrm{mM}$ citric acid/phosphate buffer, $5 \mathrm{mM} \mathrm{K}_{4} \mathrm{Fe}(\mathrm{CN})_{6}, 5 \mathrm{mM} \mathrm{K}{ }_{3} \mathrm{Fe}(\mathrm{CN})_{6}, 150 \mathrm{mM} \mathrm{NaCl}, 2 \mathrm{mM} \mathrm{MgCl} 2,1 \mathrm{mg} / \mathrm{ml}$ $\mathrm{X}-\mathrm{Gal}$ ) (All reagents from Sigma-Aldrich) ${ }^{62}$. Cells were counted in at least five fields for each slide, for a total of over 100 cells. The percentage of senescent cells was calculated by the percentage of the number of blue cells in the field.

Immunofluorescence staining of $\gamma \mathrm{H} 2 \mathrm{AX}$ and RAD51. Cells were cytospun onto a glass slide at $400 \mathrm{~g}$ for $5 \mathrm{~min}$ and then fixed for $30 \mathrm{~min}$ in $4 \%$ PFA and permeabilized and blocked in $0.8 \%$ Triton X-100, 10\% FBS/1\% BSA (SigmaAldrich) in PBS for $15 \mathrm{~min}$ at room temperature. Mouse anti-mouse $\gamma \mathrm{H} 2 \mathrm{AX}$ (ser139) (Upstate clone JBW301 \#05-636) and rabbit anti-mouse RAD51 (Santa Cruz Biotechnology H92 \#sc-8349) were diluted in TBS containing 10\% FBS and $1 \% \mathrm{BSA}$ and incubated overnight at $4{ }^{\circ} \mathrm{C}$. Slides were then washed three times with PBS and subsequently incubated with 1:200 donkey anti-mouse DL 488 (Jackson/Stratech 715-485-150) and 1:200 goat anti-rabbit Cy3 (Jackson/Stratech 111-165-144) in TBS containing DAPI $0.2 \mu \mathrm{g} / \mathrm{ml}, 10 \% \mathrm{FBS}, 1 \%$ BSA for $1 \mathrm{~h}$ at room temperature in the dark. Slides were then washed five times at 10 min each with PBS. Slides were briefly washed in water and air-dried before mounting with Mowiol-DABCO and a coverslip. Cells were counted in at least five fields for each slide, for a total of over 100 cells per condition.

May-Grunwald Giemsa staining. $10^{5}$ cells were cytospun for $5 \mathrm{~min}$ at $300 \mathrm{~g}$ onto glass slides. Slides were then stained with May-Grunwald solution (SigmaAldrich) for $3 \mathrm{~min}$ at room temperature. After washing in water, they were incubated for $20 \mathrm{~min}$ in Giemsa solution (Sigma-Aldrich) (1:20 in water). Slides were washed again in water before being mounted with Mowiol.

Nitro blue tetrazolium (NBT) reduction assay. NBT reduction assay were performed to determine myeloid differentiation. $0.1 \%$ of NBT (final concentration) was added to the liquid culture or semi-solid MethoCult and incubated at $37^{\circ} \mathrm{C}$ $\mathrm{CO}_{2}$ incubator for $3 \mathrm{~h}$ and $12 \mathrm{~h}$, respectively. Cells were then washed in PBS and the differentiated cells were indicated by the deposition of dark blue insoluble formazan (NBT-positive cells) and the percentage of differentiated cells was counted under microscopy. At least 200 cells were counted in most cases.

shRNAs. Mouse Parp1-targeting sequences were cloned into pSuper-RetroPuro retroviral vector (OligoEngine). The target sequences for mouse Parp1 gene are 5'-TAAAGAAGCTGACGGTGAA-3' (targeting the positions

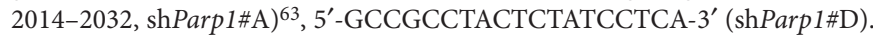
Human HOXA9 and scrambled shRNAs were cloned in to GIPZ lentiviral vector. The target sequence for the human HOXA9 gene is $5^{\prime}$-GTGGTT CTCCTCCAGTTGATA- $3^{\prime}$ (HOXA9 shRNA) ${ }^{44}$. The scrambled sequence is $5^{\prime}$ GCGAAAGATGATAAGCTAA-3'.

Expression of mouse Parp1-targeting shRNA in NIH3T3 cells. $1.6 \times 10^{5}$ cells were plated in each well of six well-plates and allowed to attach for $6 \mathrm{~h}$ when the cells were transduced with $200 \mu$ l of concentrated virus expressing i) the empty vector, ii) the scrambled or iii) shRNA targeted against mouse Parpl and $5 \mu \mathrm{g} / \mathrm{ml}$ of polybrene in a final volume of $2 \mathrm{ml}$. After $24 \mathrm{~h}$, the medium was replaced fresh one containing $1.5 \mu \mathrm{g} / \mathrm{ml}$ puromycin (Invitrogen) for a $3-\mathrm{d}$ selection. Cells were then collected for RT-qPCR and western blot analysis.

Western blot analysis. Cells were collected by centrifugation, and the cell pellet was suspended in lysis buffer $(0.02 \%$ SDS, $0.5 \%$ Triton-X, $300 \mathrm{mM} \mathrm{NaCl}$, $20 \mathrm{mM}$ Tris- $\mathrm{HCl}$ pH 7.5, 1 mM EDTA, $1 \mathrm{mM} \mathrm{DTT}, 10 \mathrm{mM} \mathrm{NaF}, 2 \mathrm{mM} \mathrm{Na}_{3} \mathrm{VO}_{4}$ ) containing $1 \times$ protease inhibitors (Roche) and incubated on ice for $30 \mathrm{~min}$. After centrifugation at $16,000 \mathrm{~g}$ for $15 \mathrm{~min}$ at $4{ }^{\circ} \mathrm{C}$, the supernatant containing total cell extract was collected and kept at $-80^{\circ} \mathrm{C}$. Proteins from cell extracts were quantified using the OD $660 \mathrm{~nm}$ Assay (Pierce). $10 \mu \mathrm{g}$ of cell extracts were loaded on a $12 \%$ polyacrylamide gel and then electrophoretically transferred onto a Hybond-PVDF membrane (GE Healthcare). The membrane was incubated for $1 \mathrm{~h}$ at room temperature in blocking buffer (TBS-T containing 8\% skimmed milk) to block nonspecific protein binding, and then it was incubated 
at $4{ }^{\circ} \mathrm{C}$ overnight with the primary antibody (Supplementary Table 7). After four washes with TBS-T, the membrane was incubated for $1 \mathrm{~h}$ with the horseradish peroxidase (HPR)-conjugated antibody, anti-mouse or anti-rabbit (Jackson ImmunoResearch) diluted in blocking buffer. Antibody binding was visualized using the ECL Prime western blotting detection system (GE Healthcare).

Immunoprecipitation assay. Cells were lysed as above (with a reduced $\mathrm{NaCl}$ concentration to $200 \mathrm{mM}$ ). The $500 \mu \mathrm{g}$ of total cell lysates were incubated with $1 \mu \mathrm{g}$ anti-FLAG antibody at $4{ }^{\circ} \mathrm{C}$ for $12 \mathrm{~h}$ with rotation. Then protein A-conjugated beads were added to precipitate the protein complex and incubated at $4{ }^{\circ} \mathrm{C}$ for $1 \mathrm{~h}$ with rotation. Beads were then washed five times with reduced $\mathrm{NaCl}$ cell lysis buffer and eluted with $50 \mu \mathrm{l}$ of $2 \%$ SDS-Tris buffer.

Real time Quantitative PCR. RNA was extracted by using a kit from Fermentas and was reverse transcribed using SuperScript III from Invitrogen. qPCR was performed by using SYBR Green or Taqman probes on an ABI 7900HT Fast Real-Time PCR System (Applied Biosystems) using primers (Supplementary Table 8). Gapdh was used a housekeeping gene. Relative expression levels were calculated using the $2^{-\Delta \Delta C T}$ method (ref. 64).

In vivo plasmid end-joining assay. The in vivo plasmid end-joining assay was performed as described ${ }^{65}$. Briefly, a DSB is generated in the lacZ gene sequence of the plasmid PUC18 by EcoRI digestion. Nuclear extracts from pre-leukemic cells carrying the above-mentioned fusion oncoproteins were obtained by using the Nuclear Extraction Kit (Pierce). $2 \mu \mathrm{g}$ of PUC18 plasmid was digested with EcoRI (Fermentas), dephosphorylated (Fermentas), separated on a 1\% agarose gel and extracted using a column-based method (Qiagen). $5 \mu \mathrm{g}$ of nuclear extracts were then incubated in NHEJ buffer (50 mM triethanolammine $\mathrm{HCl}$ pH7.5, $60 \mathrm{mM}$ potassium acetate, $0.5 \mathrm{mM}$ magnesium acetate, $250 \mu \mathrm{M}$ dNTPs, $10 \mathrm{mM}$ ATP, $5 \mathrm{mM}$ dTT, $500 \mu \mathrm{g} / \mathrm{ml} \mathrm{BSA}$ ) for $5 \mathrm{~min}$ at $37^{\circ} \mathrm{C}$. $250 \mathrm{ng}$ of digested dephosphorylated plasmid were then added to the reaction in 50-100 $\mu$ l final volume and incubated for $24 \mathrm{~h}$ at $18^{\circ} \mathrm{C}$. The next day, the DNA was purified using a column-based method (Qiagen) and $30 \mathrm{ng}$ were used to transform Escherichia coli and plate them on LB-agar plates $+160 \mu \mathrm{g} / \mathrm{ml} \mathrm{X-Gal} \mathrm{(Sigma-Aldrich)} \mathrm{and} 1 \mathrm{mM} \mathrm{IPTG} \mathrm{(Sigma-}$ Aldrich). Colonies were counted and plotted. The percentage of misrepair was calculated as the percentage of blue colonies versus the total number of colonies.

Homologous recombination (HR) assay. For the HR assay, $0.5 \times 10^{6} \mathrm{U} 2 \mathrm{OS}-$ DR cells were plated into six-well plates. After $24 \mathrm{~h}$, cells were co-transfected with I-SceI expression (pCBASce, $1.25 \mu \mathrm{g})$, oncogenes of interest $(1.25 \mu \mathrm{g})$ and RFP constructs $(0.2 \mu \mathrm{g})$ using Lipofectamine 2000 (Invitrogen) according to the manufacturer's protocol. The percentage of $\mathrm{GFP}^{+}$cells was measured by flow cytometry $3 \mathrm{~d}$ after transfection and normalized against the percentage of $\mathrm{RFP}^{+}$cells for transfection efficiency. Relative HR efficiency was then normalized to empty vector.

In vivo experiments. All the experimental procedures were approved by the King's College London Animal Welfare and Ethical Review Body and conform to the UK Home Office regulations. For all in vivo experiments, mice were distributed into their respective groups randomly. Investigators were not blinded to the sample identity. Mice were considered leukemic when an engraftment of donor cell was detected.

We established humanized models of AML1-ETO and PML-RAR $\alpha$ leukemia in sub-lethally irradiated NOD/SCID/IL2Rg-/- (NSG, 1 dose $200 \mathrm{RADs}$ ) by transplanting $2 \times 10^{6}$ Kasumi (intrafemoral, i.f.) and $10^{5} \mathrm{NB} 4-\mathrm{LR} 2$ or $10^{5} \mathrm{THP} 1$ (intravenous, i.v.) cells. The day after the transplantation, mice were split into two groups with an equal number of males and females in each group and given intraperitoneal injections of vehicle $(10 \% \mathrm{HBC})$ or olaparib $(25 \mathrm{mg} / \mathrm{kg}$ in $10 \%$ HBC) daily for 2-4 weeks. The maximum tolerable dose was calculated by in vivo dose-response experiments. Mice were monitored daily until they developed symptoms of leukemia, when they were culled, and bone marrow, spleen and liver was harvested and analyzed by FACS. The engraftment of human donor cells was defined as $\mathrm{CD} 45^{+} \mathrm{CD} 33^{+}$double-positive by FACS.

For Hoxa9-knockout studies, we intravenously injected $10^{6}$ MLL-AF9 leukemic cells (wild type or Hoxa9 $9^{-/-}$background) together with $2 \times 10^{5}$ bone marrow rescue cells into lethally irradiated female $\mathrm{C} 57 \mathrm{Bl} / 6$ mice ( 2 doses of irradiation,
550 rads each). For drug studies, the control cohort received vehicle (10\% 2-hydroxpropyl-beta-cyclodextrin, HBC, Sigma-Aldrich) and the PARPi treatment group received daily olaparib $50 \mathrm{mg} / \mathrm{kg}$ in $10 \% \mathrm{HBC}$ for 2-4 weeks.

For mouse MLL-AF9 LSC in vivo studies involving PARPi and GSK3i, MLL-AF9 LSCs were pretreated in R20/20 with $4 \mathrm{mM} \mathrm{LiCl}$ or $1 \mu \mathrm{M}$ olaparib or a combination thereof for $3 \mathrm{~d}$. Equal number $0.2 \times 10^{6}$ of live cells were transplanted into sublethally irradiated $\mathrm{C} 57 \mathrm{Bl} / 6$ female mice. Continuous olaparib and $\mathrm{Li}_{2} \mathrm{CO}_{3}$ treatment was commenced on the day after irradiation and injection of cells. Mice were given $0.4 \%$ lithium carbonate-containing diet (Harlan Laboratory) along with olaparib by intraperitonal injection every other day for 4 weeks. The engraftment of mouse donor cells was defined as CD $45.1^{+}$CD $45.2^{-}$by FACS.

For in vivo experiments with primary AML samples, $10^{5}$ patient-derived leukemic cells carrying $M L L$ rearrangement (AML1) transduced with a firefly luciferase-expressing plasmid were transplanted via by i.f. injection into the right femur of the NSG mice. Three days after transplantation, mice were supplemented with $0.4 \% \mathrm{Li}_{2} \mathrm{CO}_{3}$-containing diet and treated with olaparib as described above for alternative day until day 21 . After day 21 , mice were maintained on $5 \mathrm{~d}$ of $\mathrm{Li}_{2} \mathrm{CO}_{3}$ diet and alternated with $2 \mathrm{~d}$ of regular diet and water for 2 additional weeks. From day 21, the tumor burdens of the animals were detected using IVIS Lumina II (Caliper) with Living Image version 4.3.1 software (PerkinElmer). Briefly, $100 \mu \mathrm{l}$ of $30 \mathrm{mg} / \mathrm{ml}$ luciferin was injected into the animals intraperitoneally $10 \mathrm{~min}$ after injection, the animals were maintained in general anaesthesia by isoflurane and put into the IVIS chamber for photography and detection of photon emission (large binning, $F=1.2$, exposure time: $3 \mathrm{~min}$ ). The tumor burdens were measured and quantified by the same software. The animals were culled when the tumor burden was $10^{8}$ photons per second or higher.

Microarray and bioinformatic analysis. Expression profiles of AML1-ETO (22 samples, cluster 13), APL (18 samples, cluster 12), MLL (11 samples, cluster 16) patients were obtained from GEO accession: GSE1159 (ref. 32). The data was supported by performing additional gene expression analysis on an independent set of published microarray data set from GSE6891 containing AML1-ETO (37 samples), APL (25 samples), and MLL (35 samples) leukemia samples. All intensity values was adjusted, normalized and summarized in $\log _{2}$ scale using Bioconductor Affy ${ }^{66}$ (background correction: rma; normalization: quantiles; summarization: median polish). The differential expression analyses on patients with leukemia exhibiting AML1-ETO and APL (PML-RAR $\alpha$ ) against MLL were performed using Bioconductor (http://www.bioconductor.org/) with limma. $P$ values were calculated by paired two-tailed $t$-test. The expression of key genes involved in DNA repair (Supplementary Table 2) from patients with leukemia expressing AML-ETO, APL (PML-RAR $\alpha$ ) and MLL fusions was plotted in box-whisker plot using Prism5 software. GSEA was performed as described ${ }^{67}$ using published data sets ${ }^{44,45}$.

Statistical analyses. All the experimental results were analyzed using unpaired two-tailed Student's $t$-test, one-way or two-way ANOVA, as indicated in figure legends. Groups that were statistically compared shared a similar variance, as shown in the figures. $P<0.05$ was considered statistically significant The log-rank test was used to compare survival curves.

61. Yeung, J. \& So, C.W. Identification and characterization of hematopoietic stem and progenitor cell populations in mouse bone marrow by flow cytometry. Methods $\mathrm{Mol}$. Biol. 538, 301-315 (2009).

62. Dimri, G.P. et al. A biomarker that identifies senescent human cells in culture and in aging skin in vivo. Proc. Natl. Acad. Sci. USA 92, 9363-9367 (1995).

63. Choi, E.J., Kim, S.M., Song, K.J., Lee, J.M. \& Kee, S.H. Axin1 expression facilitates cell death induced by aurora kinase inhibition through PARP activation. J. Cell. Biochem. 112, 2392-2402 (2011).

64. Schmittgen, T.D. \& Livak, K.J. Analyzing real-time PCR data by the comparative C(T) method. Nat. Protoc. 3, 1101-1108 (2008)

65. Gaymes, T.J. et al. Increased error-prone non-homologous DNA end-joining-a proposed mechanism of chromosomal instability in Bloom's syndrome. Oncogene 21, 2525-2533 (2002)

66. Gautier, L., Cope, L., Bolstad, B.M. \& Irizarry, R.A. Affy-analysis of Affymetrix GeneChip data at the probe level. Bioinformatics 20, 307-315 (2004).

67. Martin, N. et al. Interplay between homeobox proteins and polycomb repressive complexes in p16INK(4)a regulation. EMBO J. 32, 982-995 (2013). 